University of Louisville

ThinkIR: The University of Louisville's Institutional Repository

Electronic Theses and Dissertations

8-2009

\title{
Microfluidic cell sorting techniques to study disease processes.
}

William Neil White

University of Louisville

Follow this and additional works at: https://ir.library.louisville.edu/etd

\section{Recommended Citation}

White, William Neil, "Microfluidic cell sorting techniques to study disease processes." (2009). Electronic Theses and Dissertations. Paper 1561.

https://doi.org/10.18297/etd/1561

This Master's Thesis is brought to you for free and open access by ThinkIR: The University of Louisville's Institutional Repository. It has been accepted for inclusion in Electronic Theses and Dissertations by an authorized administrator of ThinkIR: The University of Louisville's Institutional Repository. This title appears here courtesy of the author, who has retained all other copyrights. For more information, please contact thinkir@louisville.edu. 


\title{
MICROFLUIDIC CELL SORTING TECHNIQUES TO STUDY DISEASE PROCESSES
}

\author{
By
}

\section{William Neil White}

\author{
A Thesis \\ Submitted to the Faculty of the \\ Graduate School of the University of Louisville \\ In Partial Fulfillment of the Requirements \\ For the Degree of \\ Master of Science \\ Department of Mechanical Engineering \\ University of Louisville \\ Louisville, KY
}

August 2009 


\title{
MICROFLUIDIC CELL SORTING TECHNIQUES TO STUDY DISEASE PROCESSES
}

By

\section{William Neil White}

A Thesis Approved on

August 6, 2009

by the following Thesis Committee:

\author{
Principal Advisor
}


This thesis is dedicated

to my parents 


\section{ACKNOWLEDGMENTS}

I would like to thank my principal advisor, Dr. Palaniappan Sethu, for his guidance and support throughout this project. I would also like to thank my other committee members, Dr. Tom Berfield and Dr. Cindy Harnett, for different perspectives on results and presentation. Thanks go out to my collaborators on this project, Dr. Ashok Raj and Dr. Salvatore J. Bertolone, both from the Pediatric Hematology/Oncology Department at the University of Louisville. In terms of data analysis, I would like to thank Dr. Sam Wellhausen, Flow Cytometry Core, James Graham Brown Cancer Center, for help with running flow cytometry samples, and my fellow lab mate, Mai-Dung Nguyen, for help with cell counts. In terms of data collection, I would like to thank Tim Andrews, Pediatric Hematology/Oncology, for help with blood sample collection. I would like to thank Mark Crain, Ana Kieswetter, Joseph Lake, and Don Yeager for help with fabrication of the microfluidic lysis device. Work in this project has been supported by the Wallace H. Coulter Foundation "Early Career Award in Translational Research" and grants from NSF Partnership for Innovation and NSF EPSCoR, with thanks to Dr. Rob Keynton and Dr. Andrea Gobin. And last but not least, I would like to thank all family and friends for their support throughout my time as a graduate student. 


\title{
ABSTRACT \\ MICROFLUIDIC CELL SORTING TECHNIQUES TO STUDY DISEASE PROCESSES
}

\author{
William Neil White
}

August 6, 2009

Circulating nucleated cell populations found in whole blood, including both white blood cells (leukocytes) and endotheliai cells, provide an ideal platform for studies seeking to understand the disease processes for development of drugs and treatments. This thesis presents an automated microfluidic device developed for leukocyte enrichment from peripheral blood. Briefly, the device allows for complete lysis of red blood cells and comprehensive analysis of nucleated cell populations in terms of quantity and activation status. The microfluidic lysis device was used in two Sickle Cell disease (SCD) studies to understand the effect of leukocytes in the initiation of vasoocclusive crisis. Findings suggest abnormally high baseline leukocyte counts and variance in clinicaj expression among SCD patients. Hence, a highly favorable state for an inflammatory reaction that may lead to vasoocclusive episodes exists. To ascertain risk factors in such incidents revision of current SCD patient classification is needed. 


\section{TABLE OF CONTENTS}

PAGE

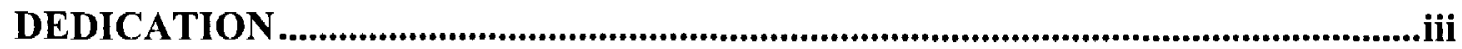

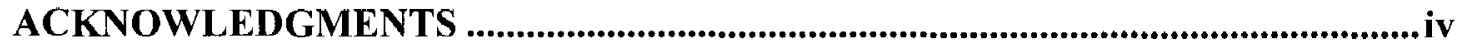

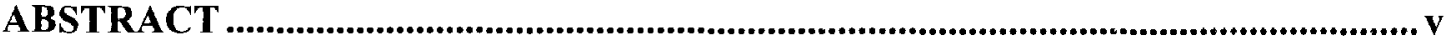

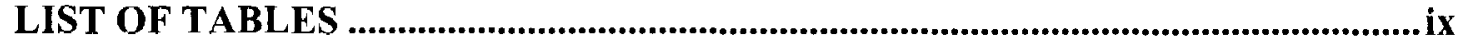

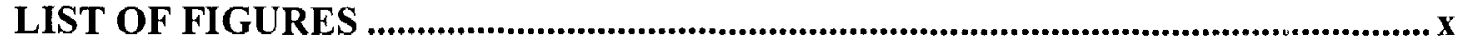

\section{CHAPTER}

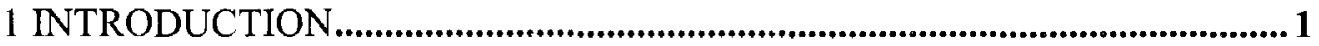

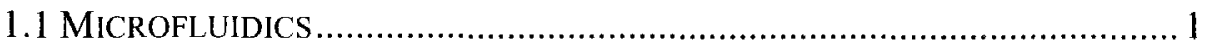

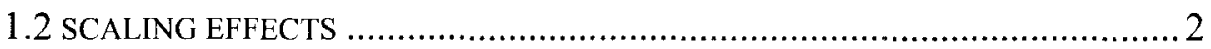

1.3 THE MICROFLUIDIC ADVANTAGE.................................................... 3

1.3.1 Conventional Enrichment Techniques .............................. 3

1.3.2 Addressing Flaws in Conventional Techniques .................... 5

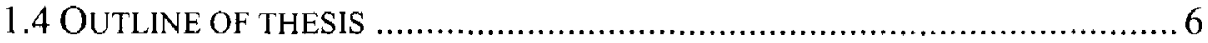

2 THE MICROFLUIDIC LYSIS DEVICE .......................................................8

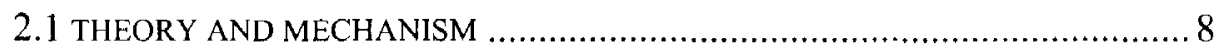

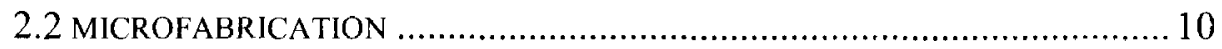

2.3 PROTOCOL FOR RUNNING LYSIS DEVICE .......................................... 12

2.3.1 Sample Collection ........................................................... 12

2.3.2 Prime Microfluidic Device with PBS .............................. 12

2.3.3 Preparation of Syringe Pumps and Solution..................... 13

2.3.4 Erythrocyte Lysis................................................. 14

2.4 ENABLING ANALYSIS OF UNKNOWN POPULATIONS ........................... 16

3 SICKLE CELL DISEASE ............................................................................. 18

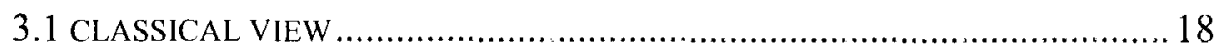

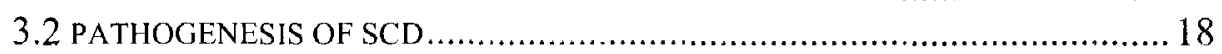

3.2.1 Red Blood Cells and Hemoglobin .................................... 19

3.2.2 White Blood Cells............................................................ 20 
3.2.3 Phenotype and Activation Markers ................................... 21

3.2.4 Potential Interactions Leading to Vasoocclusion ................ 23

3.3 SYMPTOMS AND COMMONLY PRESCRIBED TREATMENTS....................... 24

3.3.1 Characteristics of Patient Samples .................................... 24

3.3.2 Hydroxyurea .................................................... 25

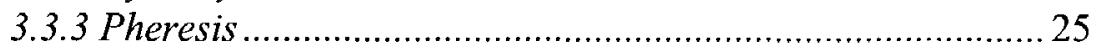

4 STUDY OF HEALTHY CONTROLS AND MILD PHENOTYPE SCD ........27

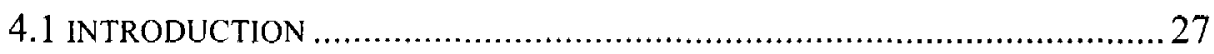

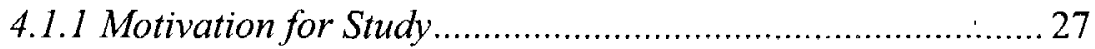

4.2 MATERIALS AND METHODS ........................................................... 28

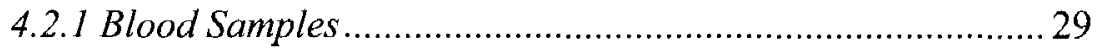

4.2.2 Sample Classification ........................................................ 29

4.2.3 Standard $\mathrm{NH}_{4} \mathrm{Cl}$ Lysis Protocol ...................................... 29

4.2.4 Standard Fico Density Gradient Separation........................ 30

4.2.5 Microfluidic Leukocyte Enrichment ................................ 30

4.2.6 Cell Counts and Flow Cytometric Analysis ...................... 31

4.2.7 Flow Cytometry Data Analysis ...................................... 31

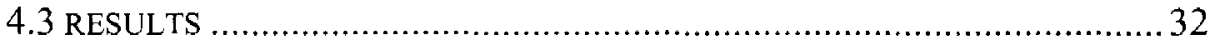

4.3.1 Erythrocyte Depletion and Leukocyte Yield...................... 32

4.3.2 Leukocyte Enrichment Process Induced Activation ............. 33

4.3.3 Comprehensive Evaluation of Leukocyte Activation Markers in SCD....................................................... 34

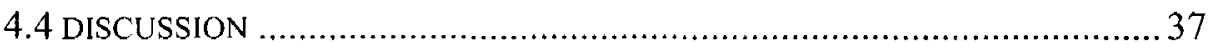

5 STUDY OF MILD PHENOTYPE SCD AND SYMPTOMATIC SCD ...........40

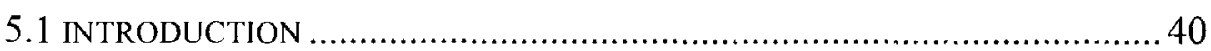

5.1.1 Motivation for Study .............................................. 40

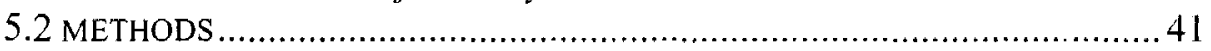

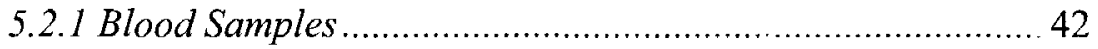

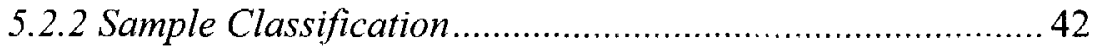

5.2.3 Microfluidic Leukocyte Enrichment ................................ 42

5.2.4 Flow Cytometric Analysis ................................................ 43

5.2.5 Flow Cytometry Data Analysis ...................................... 44

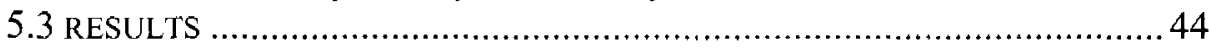

5.3.1 Erythrocyte Depletion and Leukocyte Yield.......................45

5.3.2 Leukocyte Activation Markers in SCD ................................ 46

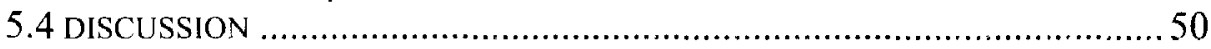

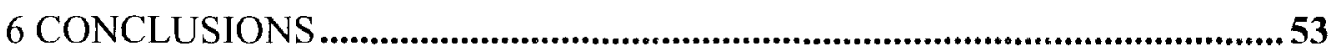

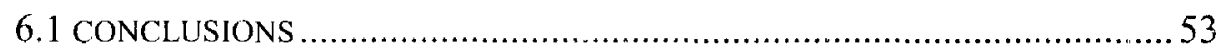

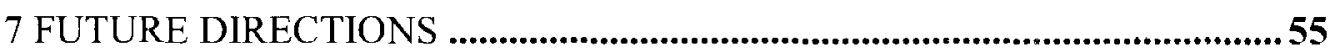

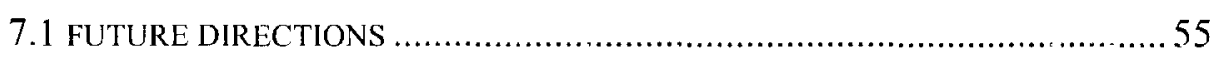


7.1.1 Device Automation ............................................................. 55

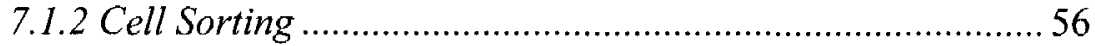

7.1.3 Analysis of Unknown Cell Populations............................. 57

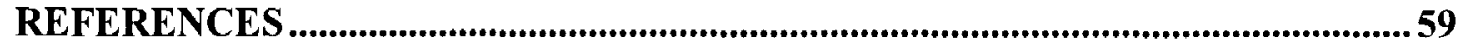

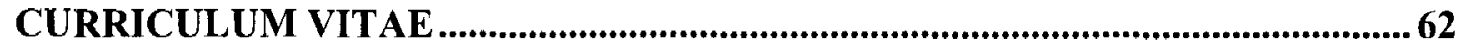




\section{LIST OF TABLES}

TABLE

PAGE

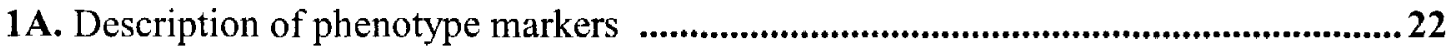

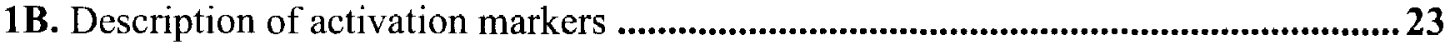

2. Cell types with corresponding phenotype and activation markers .............................32

3. Comparison of activation between enrichment techniques ........................................34

4. Nucleated cell populations and corresponding phenotype and

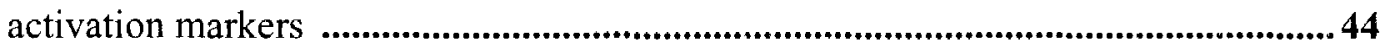

5. Ranked values of percentage of total nucleated cells .............................................49

6. Ranked values of percentage of regioned nucleated cell populations .........................50 


\section{LIST OF FIGURES}

1. Detailed schematic of microfluidic lysis device ..........................................................8

2. Microscope images of the device .................................................................................10

3. Schematic of device showing inlets for respective solutions and outlet ....................13

4. Comparison of unknown cell populations with different enrichment

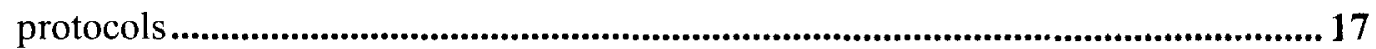

5. Structural depiction of hemoglobin chains ................................................................19

6. Types of leukocytes found in immune system .........................................................21

7. Comparison of leukocyte yield between enrichment techniques ...............................33

8. Lymphoid Panel ..................................................................................................................... 35

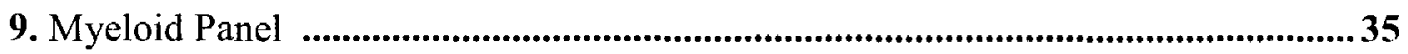

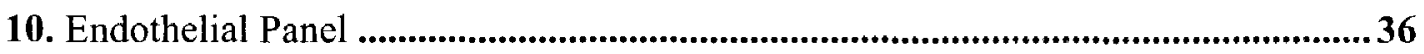

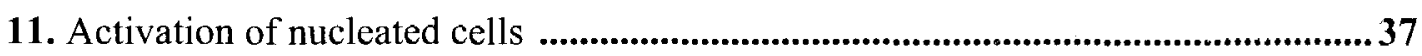

12. Leukocyte phenotype panel .........................................................................................45

13. Endothelial phenotype panel ...................................................................................46

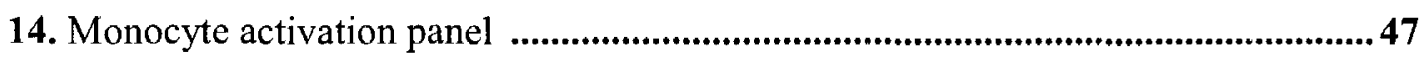

15. Granulocyte activation panel ......................................................................................4

16. Lymphocyte activation panel .........................................................................................4 48

17. Endothelial activation panel ....................................................................................48

18A. Schematic representation of automated setup for leukocyte isolation ....................56

18B. Solid Edge model of manifold for fluidic interconnects to microfluidic

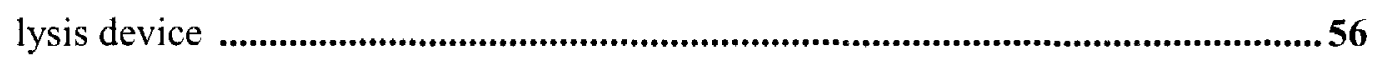

19. Schematic of proposed cell sorting device using Dean flow ………..........................57 


\section{CHAPTER I - INTRODUCTION}

\subsection{MICROFLUIDICS}

Microfluidics has been defined by George $M$. Whitesides [1] as the science and technology of systems that process or manipulate small $\left(10^{-9}\right.$ to $10^{-8}$ liters $)$ amounts of fluids, using channels with dimensions of tens to hundreds of micrometers. Emergence of this distinct field was inspired by four disciplines: molecular analysis, biodefense, molecular biology and microelectronics. With origins in analysis, success with transforming analytical methods such as gas-phase chromatography and capillary electrophoresis to the microscale by capillary format influenced other applications of microfluidics. A primary stimulus for sudden growth of the microfluidic field came in the 1990s with the US Department of Defense developing small-scale systems to detect chemical and biological threats. Molecular biology acted as a third motivational source with the wave of genomics because of the need for high-throughput analysis with greater sensitivity and resolution. Application of fabrication techniques such as photolithography from silicon microelectronics and microelectromechanical systems (MEMS), nonetheless, has been the most essential for the development of microfluidic technologies. Because of the material restraints of silicon, steel and glass with biological samples due to gas permeability, these fabrication techniques were not directly applicable at first; although, such materials are now used to build specialized system that require 
thermal or magnetic support. Hence, an optically transparent, soft and biologicallyfriendly elastomer known as poly(dimethylsiloxane), or PDMS, was developed.

Properties of PDMS make it a suitable platform for miniaturized biological studies. Soft lithographic techniques are used to fabricate PDMS devices that are capable of controlling fluid flow in molded microchannels for a variety of purposes: immunoassays, separation of proteins and DNA, formation of molecular gradients and sorting of cells. Common methods for sorting or enriching cell populations on the microscale include magnetic filtration, fluorescent activated cell sorter (FACS), hydrodynamics and inertial focusing [2]. The PDMS microfluidic lysis device described in this thesis is a nucleated cell enrichment device that takes advantage of the ability to manipulate cells in a microfluidic system to expose whole blood to hypotonic conditions for a controlled amount of time in a constant environment.

\subsection{SCALING EFFECTS}

Although the study of fluid mechanics is an old discipline, interest has only moved toward fluids on a smaller scale in the past decades. In this realm fluids behavior is significantly different as the forces that act on the macroscale become negligent on the microscale and vice versa, phenomena due to scaling effects. The concept of scaling expresses variation of physical quantities of a given object or system with respect to size, while keeping other quantities (time, pressure, temperature) constant. Applying this to dimensionless parameters that convey the quality of fluid flow reveals the dominating physical quantities of the microscale. Dimensionless fluidic numbers include Reynolds 
(inertia $\div$ viscosity), Knudsen (molecular spacing $\div$ length scale), Peclet (convection $\div$ diffusion) and Weber (inertia $\div$ surface force); indicating laminar flow (low Reynolds number) and domination by molecules, diffusion over convection, and surface forces over volume effects as the dimensions get smaller [3]. Harnessing these forces allows design of unique devices for research or technical use.

\subsection{THE MICROFLUIDIC ADVANTAGE}

Interest in the field of microfluidics has become so large because of the unique advantages that working on such a small scale provides. Apparent reasons for miniaturization are small device size and minute sample or reagent volumes. Shrinking the size of a device enables or enhances characteristics, portability and placement in constrained areas, as well as the ability for mass fabrication. Use of small amounts of reagents reduces assay costs and extends limited samples. Microfluidic technologies also allow for the control of precise geometry of microstructures and constrained geometries to confine molecules or mechanical forces, by means of microfabrication. Less obvious benefits of miniaturization include increase in the ratio of surface area relative to volume and high throughput devices operating through parallel arrays. High-aspect ratio and increased throughput lead to more rapid and sensitive analysis.

\subsubsection{CONVENTIONAL ENRICHMENT TECHNIQUES}

Interrogating the immune status of an individual in terms of circulating nucleated cells generates important information on condition of health and may help to diagnose disease. Accessing these nucleated cell populations through blood sample collection is easier and 
more convenient than human expression analyses involving tumor tissues. Contained within these nucleated cells is essential genetic (DNA) and gene expression (RNA and protein) data. Phenotype or activation molecules expressed on the cell membrane also bear significance. To examine these nucleated cells in circulation, such as white blood cells (leukocytes), one must be able to enrich or sort the populations from other blood components, including red blood cells (erythrocytes), and then isolate nucleic acids from the cells of interest. Eliminating erythrocytes, which contain little genetic information, is relevant as whole blood is composed of $45 \%$ red blood cells, whereas leukocytes only make up $1 \%$.

Ideally, sample preparation in terms of sorting or enrichment takes advantage of certain cell properties. Conventional techniques sort blood leukocytes by impedance using flow cytometry and enrich cells by density and osmotic properties using Ficol density gradient separation and ammonium chloride lysis. However, maintaining a constant environment for all cells and controlling exposure time to harsh conditions with these techniques is not plausible. Because of the lack of sensitivity, cells and even certain populations are lost. Furthermore, conventional techniques activate the cells and alter the cellular phenotype, resulting in artifactual gene expression [4-6]. Hence, it is often impossible to directly compare gene expression data obtained with conventional sample preparation techniques. Additionally, protocols for conventional sample preparation techniques also vary extensively between laboratories, another source of degradation in the value of the gene expression data. 
Microarray technologies, employed to analyze gene expression data, are powerful and widely-used tools for the simultaneous measurement of mRNA abundance of thousands of genes. Despite considerable development, widespread use has been limited in clinical medicine due to analytical complexities. In a recent report, Irizarray et al [7] demonstrated significant variance in microarray analyses from different laboratories using the same analytical platforms. The variance could be minimized and consistent results obtained if the 'laboratory effect', or protocol variability, was eliminated. Weis et al [8] also examined sources of error and variance in gene expression data from different laboratories and platforms, and found that results were comparable when common platforms and procedures were employed. Such reports stress the need for uniformity in protocols and reduction of analytical variance by appropriate standardization.

\subsubsection{ADDRESSING FLAWS IN CONVENTIONAL TECHNIQUES}

Comparative functional genomics using high throughput microarrays provides an unbiased platform for genome-wide transcriptome analysis to identify differences in gene expression between a control group and well-defined patient populations. Blood leukocytes provide an ideal sample for such studies. Enrichment of leukocytes from blood without loss or artifactual activation is critical to gene expression profiling. Currently leukocyte enrichment protocols are not automated, involve several usermediated steps and are associated with cell loss and artifactual activation. Hence arises the importance of sample preparation. The microfluidic protocol introduced in this thesis addresses the flaws associated with conventional leukocyte enrichment techniques and exhibits relevance to clinical use through studies with Sickle cell disease (SCD) patients. 


\subsection{OUTLINE OF THESIS}

Microfluidics continues to revolutionize the medical field with developments that are able to encompass an entire bio/chemical laboratory on the surface of a polymer based or silicon chip. This thesis reports the use of microfluidics for applications in the biomedical field. In particular, this paper addresses the variance among conventional enrichment techniques affecting gene expression data and introduces an automated microfluidic platform for clinical studies of disease processes.

Chapter two illustrates the microfluidic lysis device. The chapter begins with the theory behind the device and the mechanism of cell lysis. Subsequent sections of the chapter describe the microfabrication of the silicon master mold of the device and how the device is prepared from a polymer using soft lithographic techniques. A thorough protocol for running the microfluidic device and the unknown cell populations recovered using this procedure wrap up the chapter.

Chapter three discusses aspects of Sickle cell disease (SCD), the disease process examined in this thesis. The classical view of SCD, focusing on the genetics of red blood cells (RBCs), is introduced, along with new studies looking at white blood cells (WBCs) in the pathogenesis of SCD, the onset of a vasoocclusive crisis in the case of this disorder. Functions of both RBCs and WBCs in the body are also presented, along with descriptions of phenotype and activation markers used to investigate SCD. Section three of this chapter states the difference between the populations analyzed in the two studies 
(Chapters 4 and 5) in this thesis and explores current treatments offered to patients in crisis.

Chapter four describes the first study of the thesis analyzing conventional techniques and the microfluidic lysis protocol using healthy controls and mild phenotype SCD patients. After an initial comparison of the conventional and microfluidic protocols, a comprehensive study between healthy controls and mild phenotype SCD patients utilizing only the microfluidic device is presented. Methods, materials, results and a brief discussion are included, along with an introduction and motivation for the study.

Chapter five explains the second study of the thesis seeking to compare mild phenotype versus symptomatic SCD patients. In this analysis only microfluidics is used to acquire data. Layout of the chapter is similar to that of chapter 4.

Chapters six and seven provide the conclusions drawn from this thesis study and possible future directions for further examinations. 


\section{CHAPTER II - THE MICROFLUIDIC LYSIS DEVICE}

\subsection{THEORY AND MECHANISM}

An automated microfluidic lysis protocol has been developed to accomplish enrichment of leukocytes and other circulating nucleated cells without loss or artifactual activation. The device (Figure 1) allows for whole blood to rapidly mix with deionized water for 10 seconds in a $50 \mu \mathrm{m} \times 150 \mu \mathrm{m}$ cross-section microfluidic channel of length $128 \mathrm{~cm}$.

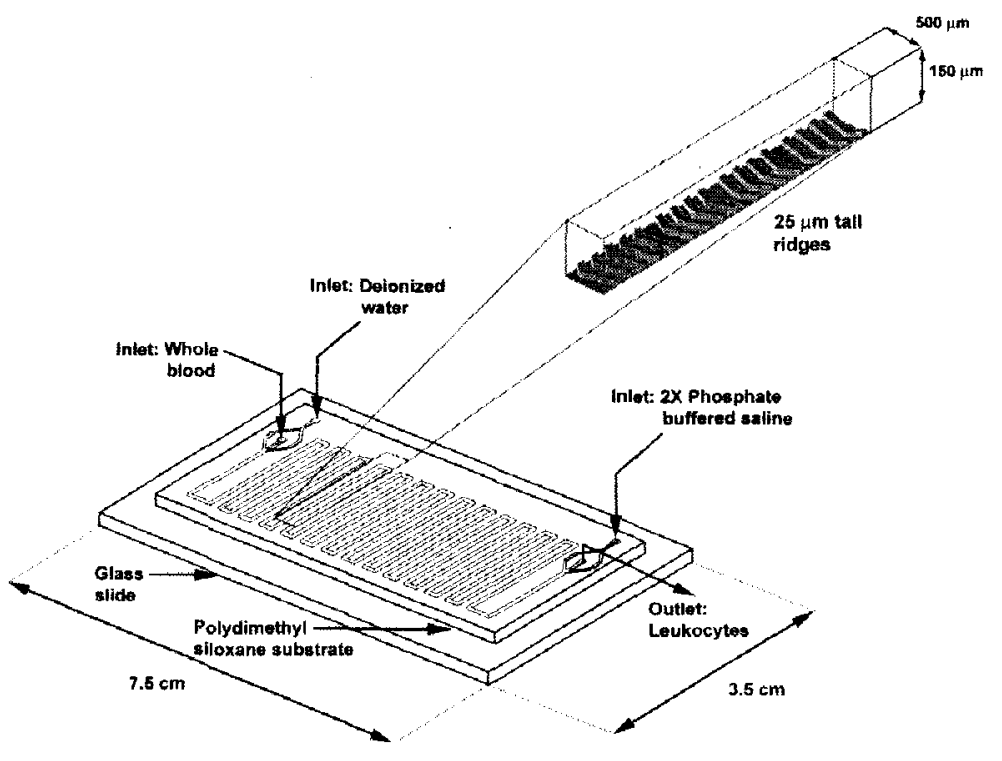

Figure 1. Detailed schematic of microfluidics lysis device.

Whole blood and deionized water are simultaneously introduced into the device via their respective inlets to achieve a 1:30 blood-to-deionized water ratio, which produces 
complete erythrocyte lysis within $10 \mathrm{~s}$. Flow rates of each solution (section 2.4 ) and total volume determine cell exposure time. Due to a low Reynolds number laminar flow exists in the microchannels, with diffusion acting as the dominating mixing force. Diffusion of deionized water occurs on this level rather quickly, but cells take longer to spread evenly throughout the channel and reach an equilibrium condition. Hence, double herringbone structures on the bottom of the channel (Figure 2) ensure chaotic mixing and that all cells are exposed to the same hypotonic conditions within the device. Characterized by Stroock et al [9], the herringbone structures lie in a staggered formation on the bottom of the channel and generate several pairs of counterrotating helical flows, which break up and mix at each transition between groove patterns. Due to a high surface-area-to-volume ratio these helical flows form rapidly in the channels as flowing particles make more contact with the channel walls after rising upon contact with the grooves. Cells exposed to hypotonic conditions in the channel allow water to cross the plasma membrane through osmosis and eventually lyse due to hydrostatic pressure. Due to the comparative small size, red blood cells lyse first, whereas more robust white blood cells withstand such conditions longer. With a short, controlled exposure time to hypotonic conditions, unwanted cell populations can be removed. After exposure to harsh conditions unlysed cells are returned to isotonic conditions at the exit of the device and fixed using $2 \%$ paraformaldehyde. The samples and reagents are automatically metered out in precise predetermined volumes, and the constant flow conditions prevent sedimentation or cell loss in the micro-channels. Complete and rapid mixing of the cells with the lysis buffer streams were visually confirmed by microscopy (Figure 2). 


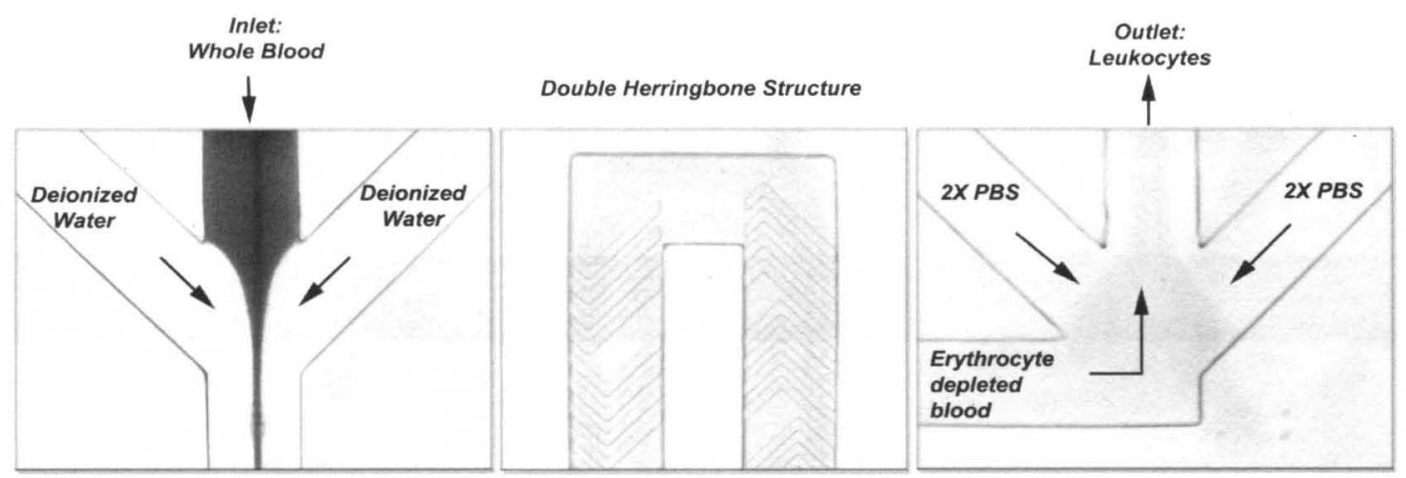

Figure 2. Microscope images of the device at the inlet, herringbone structures in the serpentine channels and outlet.

\subsection{MICROFABRICATION}

A silicon mold of the microfluidic device was fabricated using photolithographic techniques with the equipment in the University of Louisville cleanroom. To create negative replicas of the channels, AutoCAD (Autodesk, Inc., San Rafael, CA) was used to generate a transparency mask (Fineline Imaging, Colorado Springs, CO). The silicon wafer was treated with oxygen plasma in an asher (March Instruments, Concord, MA) for five minutes (100 mTorr pressure, $100 \mathrm{mV}$ power, $10 \% \mathrm{O}_{2}$ concentration) and spin coated with negative photoresist SU-8 (MicroChem, Newton, MA). After a soft exposure bake (SEB) the silicon wafer was exposed to UV light using the AB-M mask aligner (ABM, Inc., Scotts Valley, CA) followed by a post exposure bake (PEB). Finally the silicon wafer was developed in BTS-220 (VWR International, LLC) to rid of uncrosslinked photoresist and flood exposed to UV light for 60 seconds. These processes were performed twice as the microfluidic lysis device is a two layer device: channels and ridges. SU-8 100 and SU-8 50 were used to create channels and ridges of heights $25 \mu \mathrm{m}$ 
and $150 \mu \mathrm{m}$. Parameters for SU-8 100/50 to obtain these channel heights are: Spread 500/500 RPM (ramp 100/100), Spin 2000/4000 RPM for 15 seconds (ramp 500/1000), SEB $70 / 20$ minutes at $115 \mathrm{C}$, Expose $61 / 17$ seconds, PEB $13 / 5$ minutes at $115 \mathrm{C}$, Develop 15/5 minutes. To determine correct spin and spread speeds, baking times, UV exposure (based upon wavelength absorbance and exposure energy to film thickness) and developing times, guidelines were generally followed from the MicroChem data sheets on SU-8 50-100 (http://www.microchem.com/products/pdf/SU8_50-100.pdf).

The microfluidics device was fabricated using soft lithographic techniques. The elastomer poly(dimethylsiloxane) (PDMS; Dow Corning, Midland, MI) was mixed 10:1 with a cross-linker, poured on top the silicon wafer, and cured at $60 \mathrm{C}$ for $12 \mathrm{~h}$. The elastomer with the replicated channels was released, and channel access holes were punched with a 22-gauge needle. The PDMS wafer was irreversibly bonded to a glass slide via oxygen plasma (100 mTorr pressure, $100 \mathrm{mV}$ power, $10 \% \mathrm{O}_{2}$ concentration) for one minute. Access tubing (Tygon; Miami Lakes, Fl) of slightly larger diameter was press-fitted into the holes. Macro to micro interface is provided through a 15 -gauge syring needle tip (Microparts Inc., Eagan, MN), attached to the tubing on each of the inlets.

\subsection{PROTOCOL FOR RUNNING LYSIS DEVICE}

After the microfluidic device has been fabricated and tested, experiments with erythrocyte lysis are ready to begin. The following section details the modified protocol for the microfluidic device. 


\subsubsection{SAMPLE COLLECTION}

- Collect 4 milliliters of blood sample from median cubital vein, on the anterior forearm vein of patient with heparin as anticoagulant in two $2 \mathrm{ml}$ green top vaccutainers.

- Discard first $2 \mathrm{ml}$ tube as it contains dislodged mature endothelial cells (false positives).

- Resuspend the second tube to mix heparin with blood; save immediately on ice.

- Process the blood sample immediately (within one hour of collection).

\subsubsection{PRIME MICROFLUIDIC DEVICE WITH PBS}

- Fill a $1 \mathrm{ml}$ syringe with $1 \mathrm{X}$ PBS and make sure to get rid of bubbles. Connect the PBS-loaded $1 \mathrm{ml}$ syringe to inlet 1 (Figure 3) on the microfluidic device. Push the syringe containing the $1 \mathrm{X}$ PBS gently by hand until the solution flows out of inlet 2 , and then immediately clamp inlet 2 with a standard office binder clip

- Continue pushing the $1 \mathrm{X}$ PBS until fluid reaches the outlet port of the microfluidics device. Once the solution flows out of the outlet, clamp the outlet tubing with another binder clip.

- Continue pushing the $1 \mathrm{ml}$ syringe until the $1 X$ PBS flows out of inlet 3 , and clamp the inlet 3 port with another office binder clip. The microfluidics device is now fully primed. 


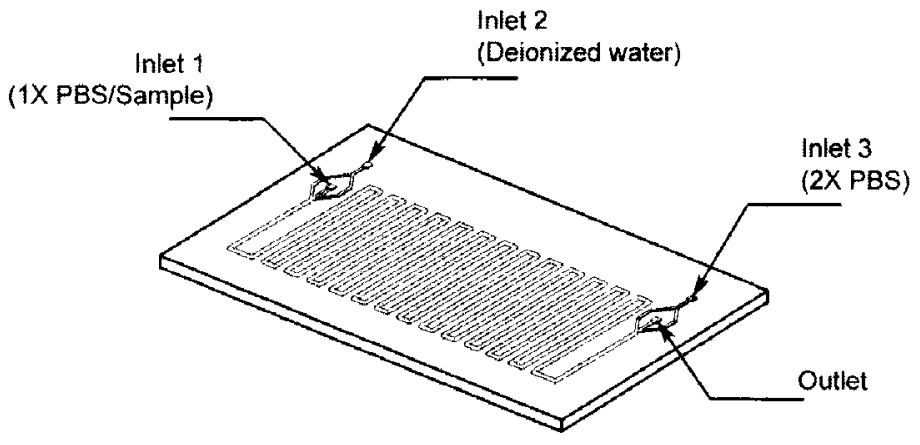

Figure 3. Schematic of device showing inlets for respective solutions and outlet.

\subsubsection{PREPARATION OF SYRINGE PUMPS AND SOLUTION}

- To calibrate the pumps follow these steps:

o For the large Harvard syringe pump (Harvard, PHD 22/2000 Part \# 702001): Set the diameter configuration to $22.5 \mathrm{~mm}$, flow rate $600 \mu 1 / \mathrm{min}$.

- For the small Harvard Syringe pump (Harvard, PHD 22/2000 Part \# 702209): Set the diameter configuration to $4.61 \mathrm{~mm}$, flow rate $20 \mu 1 / \mathrm{min}$.

- Fill one $30 \mathrm{ml}$ syringe with sterile deionized water. This can be accomplished by withdrawing the solution directly from the $50 \mathrm{ml}$ conical tube. (Label the syringe)

- Fill a second $30 \mathrm{ml}$ syringe with $2 \mathrm{X}$ phosphate-buffered-saline (PBS), $2 \%$ paraformaldehyde (PFA) using the procedure outlined in step 9. (Label the syringe)

- Fill a $1 \mathrm{ml}$ syringe with $1 \mathrm{X}$ PBS from the aliquots stored in the $4 \mathrm{ml}$ Falcon tubes, using the procedure outlined in step 9.

- Remove the clamps and connect the $30 \mathrm{ml}$ deionized water syringe to inlet 2 and the $30 \mathrm{ml} 2 \mathrm{X}$ PBS syringe to inlet 3 (make sure you don't trap bubbles in the 
tubing or microfluidics device). Remove the clamp from the outlet tubing. Connect the $1 \mathrm{X}$ PBS $1 \mathrm{ml}$ syringe into inlet 1 .

\subsubsection{ERYTHROCYTE LYSIS}

- Set all of the syringes on the proper Harvard pumps as outlined below:

- Set the two $30 \mathrm{ml}$ syringes (one containing sterile, de-ionized water and the other with $2 \mathrm{X}$ PBS, $2 \%$ PFA) together on the large Harvard syringe pump.

$\circ$ Set the $1 \mathrm{ml}$ syringe (containing $1 \mathrm{X}$ PBS) on the small Harvard syringe pump.

- Place the outlet tubing in a waste collector $(50 \mathrm{ml}$ conical tube that is labeled "waste").

- Turn on the large Harvard syringe pump (with the $30 \mathrm{ml}$ syringes) and let it run for one minute. (Make sure there is no leakage in the device or in the tubing).

- Turn on the small Harvard syringe pump and let it run for an additional minute. (Make sure there is no leakage in the device or in the tubing). Stop the pumps. The microfluidics device is now ready to be used.

- Remove the $1 \mathrm{ml}$ syringe containing $1 \mathrm{X}$ PBS from the small Harvard syringe pump.

- After obtaining a blood sample, fill the $1 \mathrm{ml}$ syringe with $0.05 \mathrm{ml}$ of sterile $1 \mathrm{X}$ PBS without trapping any bubbles. Next, fill the syringe with $0.5 \mathrm{mls}$ of blood obtained from the Eppendorf tube. (The $1 \mathrm{ml}$ syringe will now contain a final 
volume of $0.55 \mathrm{mls}$ of the blood and 1X PBS buffer.) Note: Keep the syringe vertical while filling to avoid mixing of the $0.05 \mathrm{ml}$ PBS with the blood.

- Connect the syringe containing the blood to inlet 1 and mount the syringe carefully (avoid pushing the blood through the tubing into the device) on the small Harvard syringe pump (the syringe is mounted vertical into the pump).

- Remove the outlet tubing from the "waste" tube and put a clean $50 \mathrm{ml}$ centrifuge tube in its place and set it on a bucket of ice.

- Switch on the large Harvard syringe pump first and let it run for 1 minute. Start collecting the sample from the outlet into the $50 \mathrm{ml}$ centrifuge tube

- Switch on the small Harvard syringe pump.

- Once the blood sample in the $1 \mathrm{ml}$ syringe has completely traveled through the device, stop both pumps. This should take approximately 20 minutes.

- Centrifuge the collected sample for 5 minutes at $350 \mathrm{x}$ g at room temperature with the brake off.

- Remove supernatant by placing pipette tip at the opposite side of the white pellet. Remove as much supernatant as possible, especially red cell debris, without disturbing the white pellet.

- Resuspend the sample in $1 \mathrm{ml}$ of flow buffer.

- For sample analysis using flow cytometry, add $100 \mu \mathrm{l}$ of sample to a flow cytometry tube.

- To the $100 \mu \mathrm{l}$ of sample add specified antibody. 
- Allow sample to incubate for 30 minutes at $40 \mathrm{C}$. Wash twice with flow buffer prior to flow cytometry (add $250 \mu \mathrm{l}$ of flow buffer, vortex, spin at $350 \mathrm{~g}$ for 5 minutes, resuspend in $250 \mu 1$ of flow buffer).

\subsection{ENABLING ANALYSIS OF UNKNOWN POPULATIONS}

Upon analysis of enriched nucleated cells it is clear that the microfluidic lysis device recovers populations of cells lost in conventional techniques (Figure 4a). Figure 4 shows flow cytometry scatter plots of nucleated cell populations enriched by different techniques grouped into regions by forward scatter (FSC) and side scatter (SSC) light, sorting cells based upon size and granulation. Smaller and least granulated cells that fall in Region 1 (red) are Lymphocytes. Region 2 (green) consists of larger and semigranulated Monocytes. Granulocytes, making up Region 3 (blue), are medium-sized and highly-granulated cells. These three regions are the nucleated cells known as leukocytes (refer to Section 3.2.2). Cells of interest include those in Region 4 (purple). These nucleated populations not salvaged in the conventional techniques Ficol and $\mathrm{NH}_{4} \mathrm{CL}$ lysis (Figure $4 \mathrm{~b}$ and $4 \mathrm{c}$ ) are yet to be fully characterized. Preliminary evaluation has revealed that this population of unknown cells stains for several antibodies (CD31, CD34, CD36, CD61, VEGF R2, CD133, CD138, and CD146), indicating the presence of multiple cell types, including but not limited to progenitor endothelial, mature endothelial, myelocytes, reticulocytes, megakaryocytes and other progenitor cells. Note that this may alter the population ratio to total nucleated cells that has been determined by conventional techniques. However, studies with the microfluidic device include controls to provide baseline ratios. 
(a)

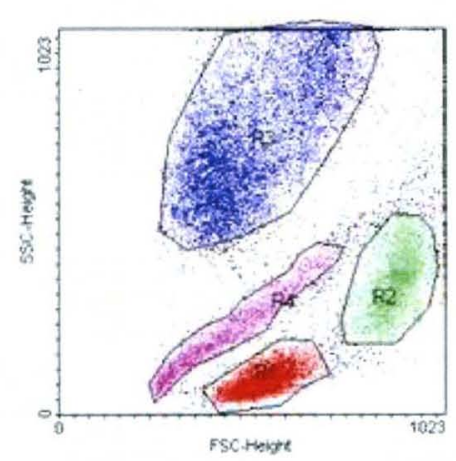

(b)

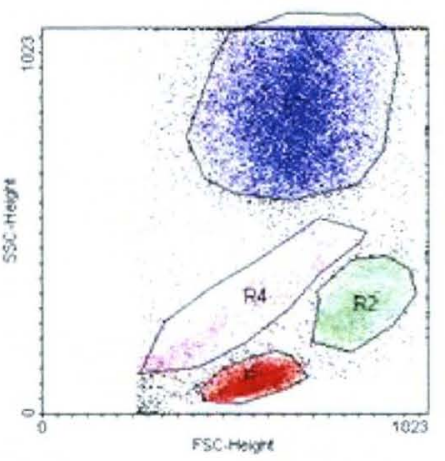

(c)

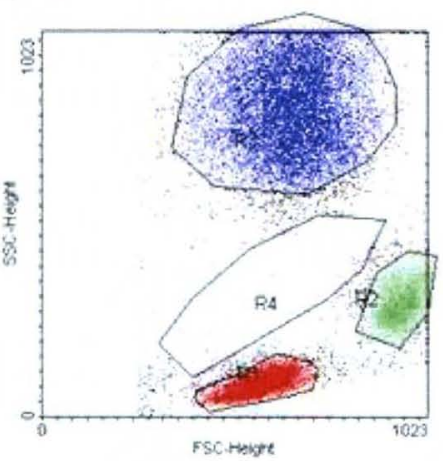

Figure 4. Comparison of unknown cell populations with different enrichment protocols. Region 1 (red) represents Lymphocytes, Region 2 (green) includes Monocytes, Region 3 (blue) consists of Granulocytes, and Region 4 (purple) contains populations not yet fully characterized. 


\section{CHAPTER III - SICKLE CELL DISEASE}

\subsection{CLASSICAL VIEW}

Sickle cell disease (SCD) is a global health problem and the molecular mechanisms leading to the manifestation of pain crisis and tissue injury are not completely understood. The classical view of SCD focuses on the primary genetic defect due to the substitution of valine for glutamic acid at the sixth position of the $\beta$-globin chain that produces $\mathrm{HbS}$, which polymerizes when deoxygenated causing it to deform, become rigid and obstruct blood flow causing acute and chronic tissue damage. This basic abnormality is responsible for the diverse manifestations of sickle cell disease that result in recurrent pain and progressive incremental infarction. Hypoxia induces polymerization of sickle erythrocytes; however, there is no consensus on the events related to or following erythrocyte sickling [10].

\subsection{PATHOGENESIS OF SCD}

HbS aggregates distort RBCs and cause them to lose their normal elasticity. Though initially a reversible process, repeated episodes of sickling cause RBCs to lose their elasticity on reoxygenation causing permanent damage. $\mathrm{HbS}$ polymerization and red-cell sickling under deoxygenated conditions are central to the pathophysiology of this disease; however, growing evidence indicates that SCD is a state of inflammation characterized 
by vascular endothelium activation and increased blood cell-endothelium interactions [11].

\subsubsection{RED BLOOD CELLS AND HEMOGLOBIN}

Red blood cells, or erythrocytes, carry oxygen and carbon dioxide between the lungs and the extremities with flow driven by the heart. Erythrocytes are non-nucleated cells with little genetic information. Hemoglobin is the protein contained within an erythrocyte that oxygen and carbon dioxide molecules bind. Structurally, the normal adult hemoglobin protein is made up of two $\alpha$-chains and two $\beta$-chains forming a quaternary complex.

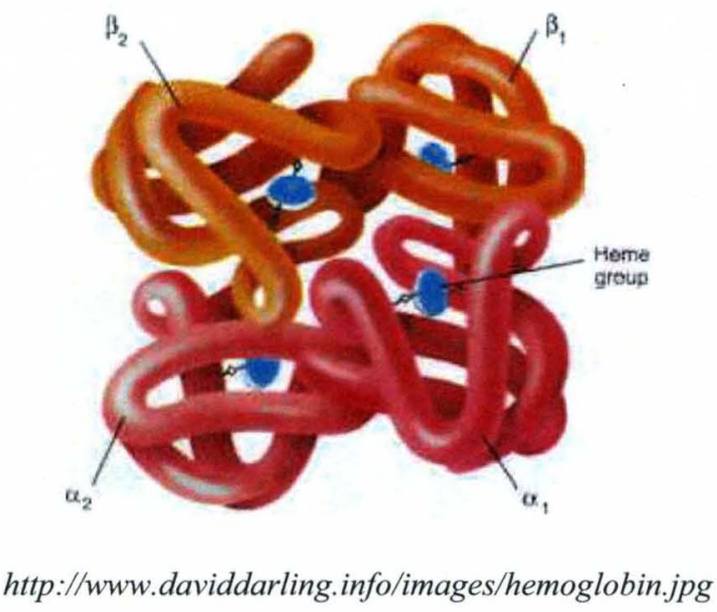

Figure 5. Structural depiction of hemoglobin chains.

Conformational changes in the protein occur during transitions from oxygenated to deoxygenated states. However, genetic defect in both copies of the $\beta$-globin gene (homozygous) leads to the formation of $\mathrm{HbS}$, or sickle hemoglobin, the root of SCD. Point mutation in the $\beta$-chain produces a hydrophobic region in the tertiary structure of the protein, leading to polymerization and sickling during deoxygenated conditions, 
becoming irreversible when flexibility is lost and preventing normal conformational changes in the protein. These sickle cells initiate and continue to promote vasoocclusive crisis, while newly formed red cells are also abnormal. Hence, treatment for the painful episode is needed. A mutation in a single allele of the $\beta$-globin gene is known as sickle cell trait and does not promote complications of SCD. Rather, sickle cell trait provides for a heterozygote advantage to malaria, disrupting parasite incubation in erythrocytes. A common therapy in SCD patients is attempt to boost fetal hemoglobin, or $\mathrm{HbF}$, which contains $\gamma$-chains in place of $\beta$-chains, contributing to higher affinity for oxygen molecules.

\subsubsection{WHITE BLOOD CELLS}

White blood cells, or leukocytes, are the defenders that compose the immune system. Leukocytes, nucleated cells with valuable genetic information, consist of three main categories: Granulocytes, Monocytes, and Lymphocytes. Granulocytes are large and highly granulated leukocytes that make up the largest population of nucleated cells and leukocytes. Categories of Granulocytes include neutrophils, eosoniphils, and basophils. Because of their non-specificity in attacking of harmful substances, Granulocytes generally arrive first at the scene of a crisis and eliminate threats by phagocytosis. Monocytes are large leukocytes that circulate in the blood and mature to macrophages upon crossing the endothelium and entering the tissue. These macrophages travel through the lymphatic system and alert a specific immune response in the lymph nodes, pancreas and spleen. Lymphocytes reside in these areas, smaller leukocytes that attack through specific antigens on the membrane surface. Included in the lymphocyte category are $\mathrm{T}$ 
helper (Th1 and Th2), Cytotoxic T lymphocytes (CTLs), T regulatory (Treg), Natural Killer (NK) and B cells. Figure 6 shows several types of leukocytes. Neither mast cells nor platelets are analyzed in the following studies of SCD. Mast cells reside in connective tissue and are involved in allergic responses. Platelets are involved in blood clotting and are pieces of larger cells called megakaryocytes.

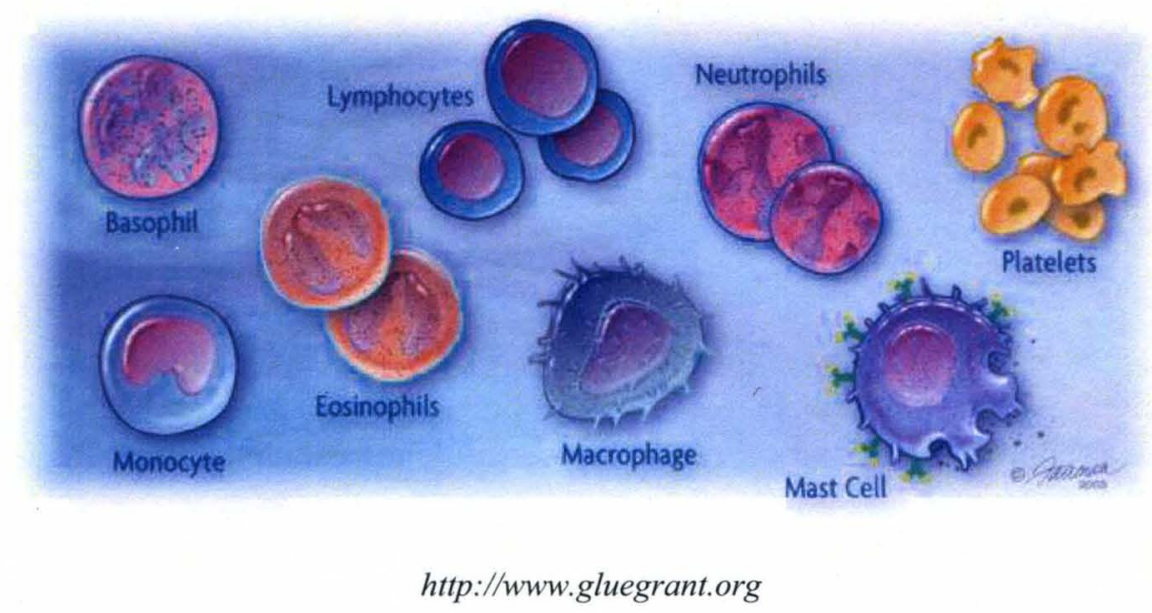

Figure 6. Types of leukocytes found in immune system.

\subsubsection{PHENOTYPE AND ACTIVATION MARKERS}

Phenotype and activation markers were selected based on current literature. Both phenotype and activation markers are molecules expressed on the membrane surface of the respective cell and their presence can be detected by antibody staining. Particular phenotype markers are expressed strongly on the respective cell and verify identity. Activation markers are expressed based on stimulus and mediate in cell adhesion. Early activation markers were used in these studies to elucidate conditions that initiate vasoocclusive crisis, and include integrin and selectin molecules. These readily accessible proteins subsist in vesicles near the cell membrane and become integrated quickly upon 
stimulus. In contrast, other activation markers proceed translation based upon gene expression response and may take days to appear. Selectins are carbohydrate-binding proteins that mediate adhesion of leukocytes to endothelial cells by forming loose bonds that allow white blood cells to roll along the endothelium. Integrins, on the other hand, are heterodimeric cell surface proteins that mediate adhesion of leukocytes to other leukocytes, endothelial cells and extracellular matrix proteins through strong bonds. Also spanning the cell membrane, integrins allow communication between the cell and its environment. Table 1 describes phenotype (1a) and activation (1b) markers used in the following SCD studies [12].

\section{Table 1}

(a) Description of phenotype markers

\begin{tabular}{|c|c|c|}
\hline $\begin{array}{c}\text { Main Cellular } \\
\text { Expression }\end{array}$ & $\begin{array}{c}\text { CD Phenotype } \\
\text { Designation }\end{array}$ & Description \\
\hline \multirow{6}{*}{ Endothelial Progenitor } & CD133 & Common EPC marker \\
\hline & CD34 & EPC marker; cell-cell adhesion; binds L-selectin \\
\hline & $C 061$ & Integrin subunit; Forms $\mathrm{EC}, \mathrm{WBC}$, and platelet aggregates \\
\hline & $C D 31$ & Platelet Endothelial cell adhesion molecule (PECAM-1) \\
\hline & VEGF R2 & Vascular Endothelium Grow Factor Receptor \\
\hline & $C D 138$ & EPC marker \\
\hline \multirow{2}{*}{ Endothelial Mature } & CD36 & Monocyte/Microvascular EC \\
\hline & $C D 146$ & Common endothelium/mature EC marker \\
\hline Granulocyte & CD66b & Granulocytes \\
\hline Monocyte/Macrophage & $\mathrm{CO} 14$ & Monocytes/Macrophages \\
\hline \multirow{5}{*}{ Lymphocyte } & CDS & T1/T2 helper cells \\
\hline & $\mathrm{CO} 4$ & Cytotoxic T Lymphocrtes \\
\hline & $\operatorname{CD} 25$ & Tregulatory cell \\
\hline & CD19 & B cell \\
\hline & CD56 & Natural Killer cell \\
\hline Leukocyte & CD45 & Leukocyte Common Antigen \\
\hline
\end{tabular}


(b) Description of activation markers

\begin{tabular}{|c|c|c|}
\hline $\begin{array}{c}\text { Main } \\
\text { Cellular } \\
\text { Expression }\end{array}$ & $\begin{array}{c}\text { CD } \\
\text { Activation } \\
\text { Designation }\end{array}$ & Description \\
\hline \multirow{3}{*}{$\begin{array}{c}\text { Endothelial } \\
\text { Mature }\end{array}$} & $C D 62 P$ & P-selectin; Leukocyte adhesion to endothelium via CD162 \\
\hline & CD106 & Vascular Cell Adhesion Molecule (VCAM-1); ligand for CD49d/CD29 \\
\hline & $\mathrm{CO54}$ & Intracellular Adhesion Molecule (ICAM-1); ligand for CD11b/CD18 \\
\hline \multirow{2}{*}{ Lymphocyte } & $\operatorname{CD} 69$ & Activation Inducer Molecule \\
\hline & CD1a & Major Histocompatibility Complex (MHC) I-like \\
\hline \multirow{8}{*}{$\begin{array}{l}\text { Monocyte \& } \\
\text { Granulocyte }\end{array}$} & $C D 64$ & Role in phagocytosis \\
\hline & co49d & Monocyte/T cell Integrin subunit; binds to VCAM \\
\hline & CD18 & Granulocyte/Monocyte Integrin subunit; Binds ICAM \\
\hline & CD162 & P-selectin glycoprotein ligand-1 \\
\hline & $C D 62 L$ & L-selectin; Leukocyte-endothelial adhesion \\
\hline & CD61 & Integrin subunit \\
\hline & $C D 116$ & Granulacyte/Monocyte Integrin subunit; Binds ICAM \\
\hline & $H L A-D R$ & MHC Complex II \\
\hline
\end{tabular}

\subsubsection{POTENTIAL INTERACTIONS LEADING TO VASOOCCLUSION}

Patients with SCD have abnormally high baseline leukocyte counts. Severity of SCD increases with leukocyte count [11]. Recent in vivo studies suggest that adherent leukocytes bind $\mathrm{RBCs}$ and contribute to the microvascular pathology that characterizes sickle cell disease (SCD), although the precise mechanism is not known. Mice expressing the trait for human sickle hemoglobin showed that sickle RBCs bind to adherent leukocytes in inflamed venules, contributing to vasoocclusion [13]. In vivo studies show that leukocyte subpopulations from sickle patients capture more RBCs per interacting leukocyte than the corresponding subpopulations from healthy controls. All leukocytes including lymphocytes, monocytes and neutrophils interact with sickle RBCs [14]; however, neutrophils are thought to contribute the most to vasoocclusive crisis due to high numbers in circulation [11]. 
Leukocyte-RBC interaction is not the cause of vasoocclusion, but rather the adherence of leukocytes to the endothelium impedes blood flow. Activated leukocytes send signals to endothelial cells (ECs), in turn activating the ECs and promoting adherence. Binding of monocytes to sickle cells, for instance, activates the vascular endothelium causing adhesion and leads to vasoocclusive crises [15]. Leukocyte subpopulations from sickle patients are also more adherent to ECs than healthy controls [14]. Transgenic sickle mice deficient in P- and E-selectins, which thwart leukocyte adherence to the vessel wall, are protected from vasoocclusion [13]. Hence, activation of leukocytes and the endothelium plays an important role in SCD.

\subsection{SYMPTOMS AND COMMONLY PRESCRIBED TREATMENTS}

Included in this section are characteristics that classify the three types of patients samples used in the studies found in this thesis. Commonly prescribed treatments for SCD patients with vasoocclusive episodes are also examined.

\subsubsection{CHARACTERISTICS OF PATIENT SAMPLES}

Patients in the clinical studies with the microfluidic lysis device are classified into three groups: healthy controls, mild phenotype SCD and symptomatic SCD. Healthy volunteers in this study were individuals between the ages of 20 to 60 who have no copy of the allele for sickle cell trait. Although using patients with a single copy of the allele may seem ideal for healthy controls, obtaining such volunteers is very difficult. In addition, a difference in expression of phenotype or activation markers between individuais with no copy of the allele and those with two copies is more significant. Mild phenotype SCD 
patients, ages 10 to 19 , contain both copies of the HbS allele but are not currently experiencing any complications of vasoocclusive crisis. Symptomatic SCD patients, also ages 10 to 19 , contain both copies of the $\mathrm{HbS}$ allele and are receiving pheresis treatment for recurring, painful complications of vasoocclusive crisis. Blood from these individuals was drawn prior to pheresis, with treatment received every 3 to 5 weeks while episodes persist. Clinical complications from vasoocclusive crisis include severe pain, acute chest syndrome, primary and secondary stroke, priapism and pulmonary hypertension.

\subsubsection{HYDROXYUREA}

One common treatment option for SCD patients includes hydroxyurea. Toxic to proliferating. cells, hydroxyurea inhibits the enzyme ribonucleotide reductase from producing deoxyribose sugars in DNA [16]. Hence, the drug does not actually decrease adhesion of leukocytes to RBCs or ECs by lowering activation markers; rather, hydroxyurea prevents occurrences of vasoocclusion by limiting the number of leukocytes and RBCs in the blood [17]. Lowering the baseline leukocyte count is critical for reduction of crises in SCD.

\subsubsection{PHERESIS}

Pheresis is another commonly prescribed treatment for symptomatic SCD patients. In this process blood is removed from the body to filter out particular components by density differences. Erythrocytes are exchanged in the case of SCD to rid of sickle cells participating in new vasoocclusive events, to provide added oxygen-carrying capacity 
and to decrease blood viscosity. Donor erythrocytes are transfused with other components of the blood and returned into circulation. 


\section{CHAPTER IV - STUDY OF HEALTHY CONTROLS AND MILD PHENOTYPE}

\section{$\underline{\text { SCD }}$}

\subsection{INTRODUCTION}

In this study, blood was sampled from healthy controls $(n=3)$ and mild phenotype SCD patients $(\mathrm{n}=3)$. Each sample was analyzed with microfluidics, $\mathrm{NH}_{4} \mathrm{Cl}$ mediated lysis and Ficol density gradient separation. Once the effectiveness of this device was established in a clinical setting as compared to currently available lab techniques, the panel of activation markers was expanded and a comparative approach was taken to analyze samples from healthy controls $(n=6)$ and mild phenotype SCD patients $(n=6)$ using only the microfluidic lysis device. Results were published in the journal Biomedical Microdevices [18].

\subsubsection{MOTIVATION FOR STUDY}

This protocol has been validated in the laboratory and pre-clinical settings. However, demonstration of the potential of this device to enrich leukocytes in the clinicai setting to understand disease processes has not been accomplished. In this study the clinical effectiveness of the microfluidic protocol to deplete erythrocytes (sickle and normal), produce high leukocyte yield and minimize artifactual activation was compared to conventional techniques using SCD as an example. The ability of this protocol to 
accurately determine leukocyte differential counts and their activation status in mild phenotype SCD and healthy controls was verified.

Several epidemiological studies have implicated abnormally high baseline leukocyte counts in SCD patients as a major risk factor in the development of disease related complications, with severity increasing with leukocyte count [11]. As a result, the role of sickle erythrocytes in SCD has been redefined as an irritant that provokes an inflammatory response along with activation of the endothelium [15]. Few studies have sought to understand the comprehensive effects of leukocytes and their activation status in the initiation of vasoocclusion, and all of these that have utilized conventional leukocyte enrichment protocols [19]. Accurately determining leukocyte yield and activation within homozygous SCD patients will help in the understanding and treatment of this genetic disease.

\subsection{MATERIALS AND METHODS}

This study was done in collaboration with Dr. Ashok Raj and Dr. Salvatore J. Bertolone at the center for Pediatric Hematology/Oncology, School of Medicine, University of Louisville. Facilities at the Flow Cytometry Core, James Graham Brown Cancer Center, University of Louisville were utilized to run samples, assisted by Dr. Sam Wellhausen. The following section briefly explains the process by which the experiments were carried out during this study. It includes details on patient classifications, protocols for conventional and microfluidics lysis enrichment techniques and flow cytometry sample and data analysis. 


\subsubsection{BLOOD SAMPLES}

Blood collection was approved by the Institutional Review Board of the University of Louisville. After obtaining written consent, $4 \mathrm{~mL}$ of blood were drawn from a total of 9 healthy volunteers and 9 mild phenotype SCD patients $(n=3$ for initial study and $n=6$ for expanded panel of antibodies) with sodium heparin as anticoagulant (Vacutainer ${ }^{\mathrm{TM}}$, Becton Dickinson, Franklin Lakes, NJ).

\subsubsection{SAMPLE CLASSIFICATION}

Healthy volunteers in this study were between the ages of 20 to 60 , did not have a copy of the allele for SCD and were not of any particular race. Mild phenotype SCD patients contained copies of both alleles of the sickle cell trait. Patients were of African-American descent between the ages of 10 to 19 with no vasoocclusive crisis. Refer to section 3.3 for more details on patient sample classification.

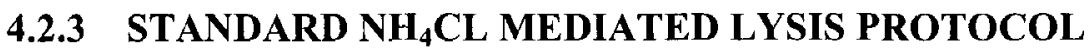

Blood samples were extracted and mixed with erythrocyte lysis buffer (Fischer Scientific, Florence, KY) in a ratio of 1:15 and mixed thoroughly by vortexing for 5 minutes. The sample was then spun down in a refrigerated centrifuge at $4^{\circ} \mathrm{C}$ for 10 minutes at $400 \mathrm{~g}$. The supernatant was discarded and the pellet was resuspended in flow cytometry buffer for further analysis. 


\subsubsection{STANDARD FICOL DENSITY GRADIENT SEPARATION}

$1 \mathrm{~mL}$ of blood sample was diluted with $2 \mathrm{~mL}$ of $1 \mathrm{X}$ phosphate buffered saline (PBS) and then layered gently on top of Ficol density gradient separation medium (GE Healthcare, Bio-Sciences AB, Uppsala, Sweden) in a $15 \mathrm{~mL}$ conical tube. This was then spun down at $500 \mathrm{~g}$ for 30 minutes in a refrigerated centrifuge at $4^{\circ} \mathrm{C}$. The first layer containing platelet rich plasma was discarded, the second layer (white band) containing the peripheral blood mononuclear cells (PBMCs) was fractionated, the third layer of Ficol solution was discarded and the pellet containing polymorphonuclear cells (PNMs) and erythrocytes was enriched and subject to $\mathrm{NH}_{4} \mathrm{Cl}$ mediated lysis protocol for elimination of erythrocytes. The PBMCs and PNMs were then combined together in flow cytometry buffer for flow cytometric analysis.

\subsubsection{MICROFLUIDIC LEUKOCYTE ENRICHMENT}

A microfluidic lysis device similar to the device described by Sethu et al [20] was used for enrichment of leukocytes and circulating nucleated cells from whole blood. Briefly, the device allows for whole blood to rapidly mix with deionized water in a 1:30 ratio for about 10 seconds in a microfluidic channel, which is sufficient for complete lysis of erythrocytes. The remaining cells are returned to isotonic conditions at the exit of the device and fixed using 2\% paraformaldehyde (PFA). Following centrifugation to remove erythrocyte debris, the remaining leukocytes were suspended in a flow buffer containing $1 \%$ bovine serum albumin (BSA), $1 \%$ PFA and $0.1 \%$ sodium azide for staining and flow cytometry. Refer to section 2.4 for an in depth protocol of the microfluidic lysis device. 


\subsubsection{CELL COUNTS AND FLOW CYTOMETRIC ANALYSIS}

For each leukocyte-enriched sample, total cell counts following lysis were obtained using a Cellometer ${ }^{\mathrm{TM}}$ (Nexcelom, Lawrence, MA), automated cell-counting system. Each sample was counted twice and averaged to obtain the total cell counts. Different subpopulations were then assessed by flow cytometry. Cells were visualized using peridin chlorophyll-a (PerCP), fluorescein isothiocyanate (FITC), phycoerythrin (PE) and allophycocyanin (APC) conjugated antibodies (BD Biosciences, San Jose, CA) against leukocyte phenotype and activation cell-surface markers (Table 2). Conjugated antibodies VEGF R2/KDR (R\&D Systems, Minneapolis, MN) and CD133 (Ancell Co., Bayport, $\mathrm{MN}$ ) were also used to visualize endothelial cells. Stained cells were washed in $1 \%$ HAB (Hank's balanced salts without calcium or magnesium, plus $1 \%$ bovine serum albumin, $0.1 \%$ sodium azide, and $1 \mathrm{mM}$ ethylenediamine tetraacetic acid), pelleted, resuspended in HAB, and analyzed on a FACSCalibur ${ }^{\mathrm{TM}}$ flow cytometer (BD Biosciences, San Jose, CA), using CellQuest ${ }^{\mathrm{TM}}$ software (BD Pharmingen). Cell activation was scored using the Rank Sum Test. All data correspond to the means of cell concentration or fluorescence intensity, \pm S.E.M., for controls $(n=6)$ and mild phenotype $\operatorname{SCD}(n=6)$.

\subsubsection{FLOW CYTOMETRY DATA ANALYSIS}

Flow cytometry data files were analyzed using WinMDI software (Scripps Institute, Flow Cytometry Core Facility, San Diego, CA). Each data file was manually gated and analyzed using different combinations of phenotype and activation markers. All fluorescence expression was normalized using controls and is represented as mean fluorescence intensity (MFI) in arbitrary units. 


\section{Table 2}

Cell Types with corresponding phenotype and activation markers

\begin{tabular}{|c|c|c|c|}
\hline Cell Type & Phenotype Marker & Cell Type & Activation Marker \\
\hline Granulocytes & CD66t & \multirow{2}{*}{ Granulocytes } & $\mathrm{CD} 18$ \\
\hline Granulocyte sub-population & $\mathrm{CD} 66+/ \mathrm{CD} 49 \mathrm{~d}+$ & & CD11b \\
\hline Monocytes & $\mathrm{CD} 14+$ & \multirow{3}{*}{ Monocytes } & CD18 \\
\hline Monocytes/Macrophages & $\mathrm{CD} 36+$ & & CD11b \\
\hline Myelocytes & $\mathrm{CD} 11 \mathrm{~b}+/ \mathrm{CD} 66+/ \mathrm{CD} 49 \mathrm{~d}+$ & & HLA-DR \\
\hline Th1 and Th2 & $\mathrm{CD} 4+1 \mathrm{CD}_{3}+$ & Lymphocytes & CD1a \\
\hline$C T L$ & $\mathrm{CD} 4-1 \mathrm{CD} 3+$ & \multirow{4}{*}{ Endothelial Cells } & $\mathrm{CD} 62 \mathrm{P}$ \\
\hline$B$ cells & $\mathrm{CD} 4 / \mathrm{CD} 25-1 \mathrm{CD} 56-1 \mathrm{CD} 3-$ & & CD106 \\
\hline T-regulatory cells & $\mathrm{CD} 4+/ \mathrm{CD} 25+$ & & $\mathrm{CD} 36$ \\
\hline Natural Killer cells & $\operatorname{CD} 56 t$ & & CD54 \\
\hline \multirow{2}{*}{ Mature Endothelial cell } & $\mathrm{CD} 146+/ \mathrm{CD} 36+$ & & \\
\hline & $\mathrm{CD} 146+/ \mathrm{CD} 31+$ & & \\
\hline \multirow{4}{*}{ Progenitor Endothelial cells } & $\mathrm{CD} 133+/ \mathrm{CD} 34+$ & & \\
\hline & VEFG R2 + & & \\
\hline & VEGF R2+/CD34t & & \\
\hline & VEFG R2+/CD133+ & & \\
\hline
\end{tabular}

\subsection{RESULTS}

This section summarizes the results comparing the microfluidics protocol to conventional techniques in terms of cell loss and artifactual activation. Comprehensive analysis using the microfluidic protocol is also presented. Graphs and tables are provided.

\subsubsection{ERYTHROCYTE DEPLETION AND LEUKOCYTE YIELD}

Blood samples were drawn from healthy controls and mild phenotype SCD patients and leukocytes were enriched using microfluidic lysis, conventional $\mathrm{NH}_{4} \mathrm{Cl}$ mediated lysis and Ficol density gradient separation. Circulating nucleated cells were phenotyped using fluorescently labeled antibodies as CD3+CD4+ Th1 and Th2, CD3+CD4- CTL, CD19+ B cells, CD14+ Monocytes and CD66b+ Granulocytes and evaluated using 4 color flow cytometry. Results in actual cell counts per $\mathrm{mL}$ of whole blood (Figure 7) indicate that 
microfluidic leukocyte enrichment resulted in significantly higher cell yield for all cell types in both healthy controls and mild phenotype SCD patient samples. Also, flow cytometry confirmed absence of erythrocytes or erythrocyte debris.
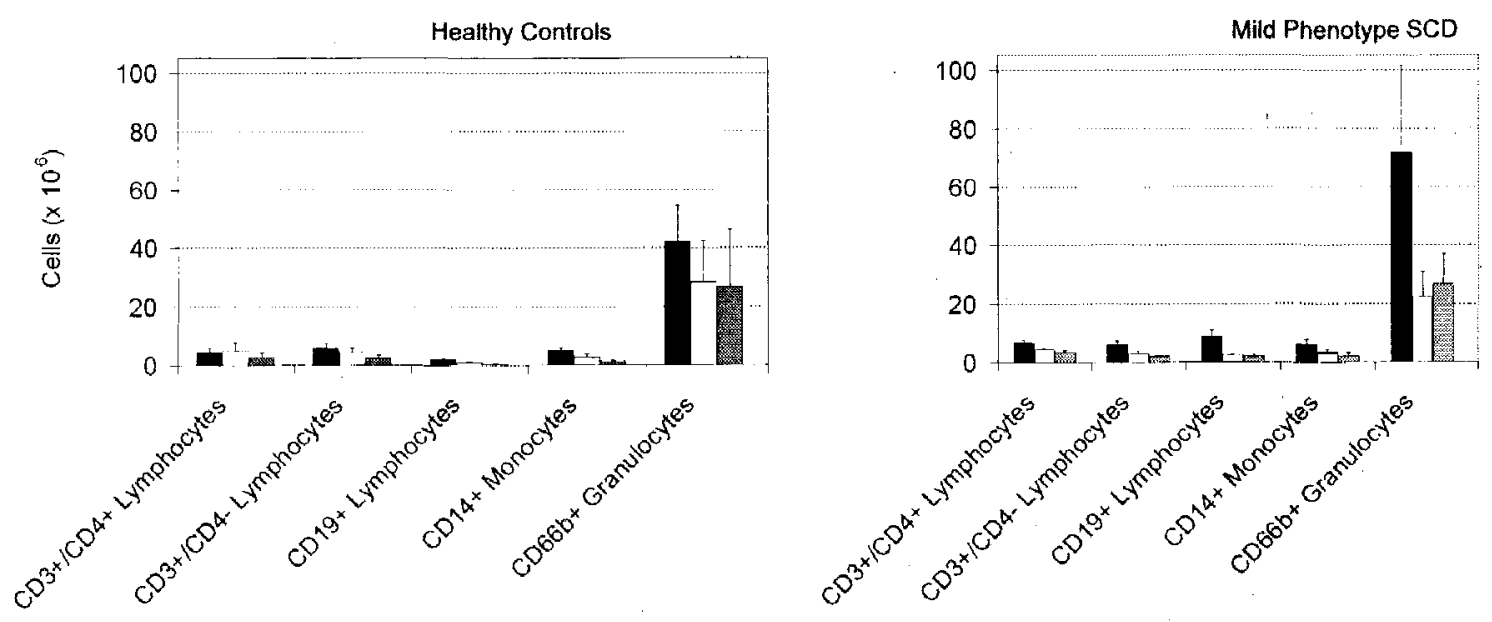

- Microfluidics $\square$ Lysis Ficol

Figure 7. Comparison of leukocyte yield between enrichment techniques.

\subsubsection{LEUKOCYTE ENRICHMENT PROCESS INDUCED ACTIVATION}

Phenotyped leukocytes using each of the aforementioned techniques were evaluated for expression of early activation markers. Lymphocytes were not scored for activation as $\mathrm{T}$ and B Lymphocyte activation typically requires $>24$ hours and most enrichment protocols last $\sim 30-60$ minutes. Cells enriched using Ficol density gradient separation were also not scored, since Granulocytes enriched via Ficol density gradient separation require $\mathrm{NH}_{4} \mathrm{Cl}$ mediated lysis to eliminate contaminating erythrocytes. Therefore we compared expression of early activation markers in Monocytes and Granulocytes enriched using microfluidics and $\mathrm{NH}_{4} \mathrm{Cl}$ mediated lysis. Monocytes were analyzed for expression of integrins $\mathrm{CD} 11 \mathrm{~b}$ and $\mathrm{CD} 18$ and Major Histocompatibility Complex II 
(HLA-DR) whereas granulocytes were analyzed for expression of integrins CD1 $1 \mathrm{~b}$ and CD18. Results (Table 3 ) indicate lower expression of early activation markers following enrichment with microfluidics for both healthy controls and mild phenotype SCD samples.

Table 3

Comparison of activation between enrichment techniques

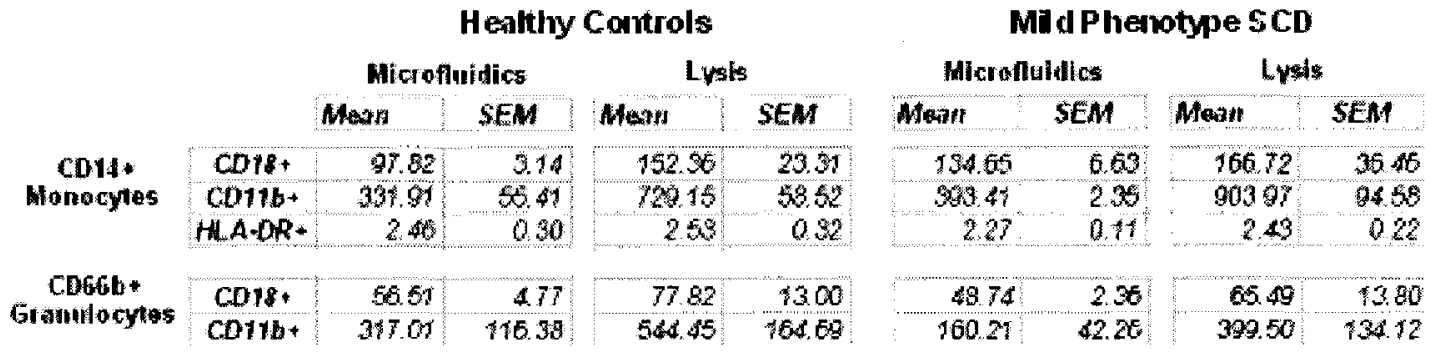

\subsubsection{COMPREHENSIVE EVALUATION OF LEUKOCYTE ACTIVATION MARKERS IN SCD}

Controls and mild phenotype SCD samples were analyzed comprehensively using the microfluidic enrichment protocol. Leukocytes and other circulating nucleated cell populations were phenotyped and their counts were determined. Activation markers for several leukocyte and circulating endothelial cell populations were also measured. Circulating nucleated cells were phenotyped and split into the following panels: Lymphoid (Figure 8), Myeloid (Figure 9), Mature Endothelial and Endothelial Progenitor (Figure 10). Lymphoid panel included CD3+CD4+ Th1 and Th2, CD3+CD4- CTL, CD4+CD25+ Treg, CD56+ NK and CD4-CD25-CD56-CD3- B cells. Myleoid panel consisted of CD66b+ Granulocytes, CD11b+CD66b+CD49+ Myelocytes, CD66b+CD49+ Granulocyte subpopulation, CD14+ Monocytes and CD36+ 
Monocytes/Macrophages. Mature Endothelial panel included CD146+CD36+ and CD146+CD31+. Progenitor Endothelial panels consisted of CD133+CD34+, VEGF R2+CD133+, VEGF R2+ and VEGF R2+CD34+. Expression of activation markers (Figure 11) was quantified for CD11b, CD18 and HLA-DR on Monocytes, CD11b and CD18 on Granulocytes, CD1a on Lymphocytes and ICAM-1 (CD54), VCAM-1 (CD106), P-Selectin (CD62p) and CD36 on circulating endothelial cells.

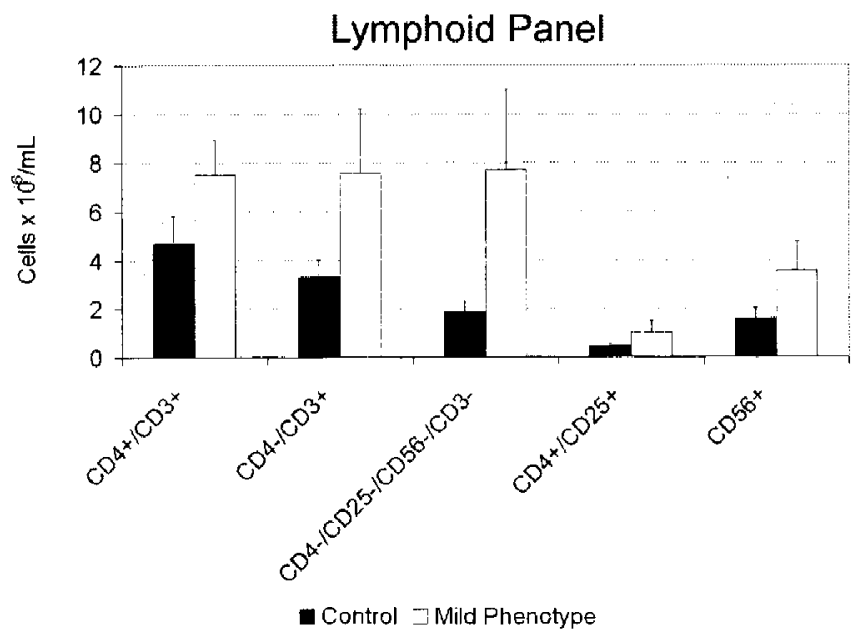

Figure 8. Lymphoid panel.

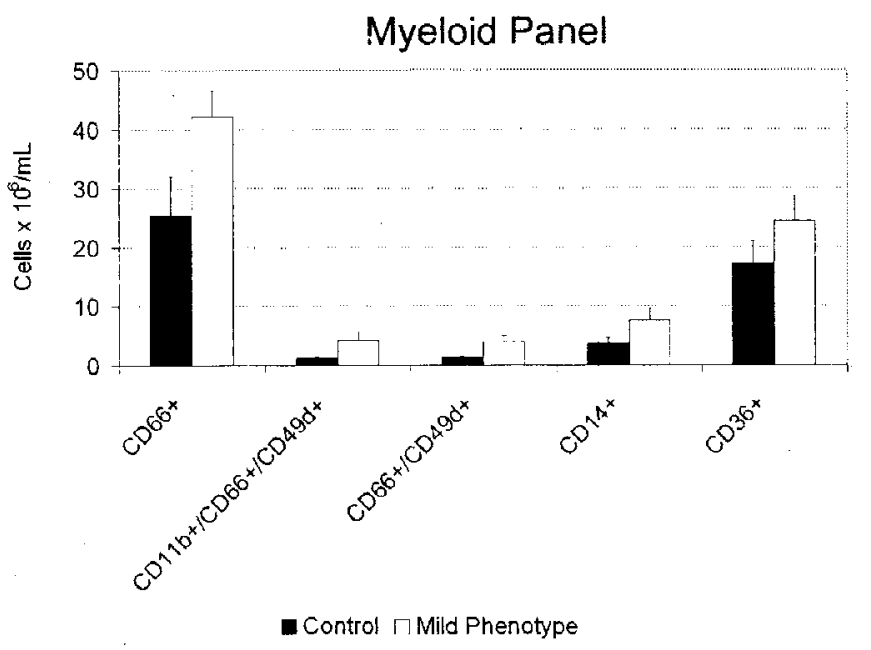

Figure 9. Myeloid panel. 

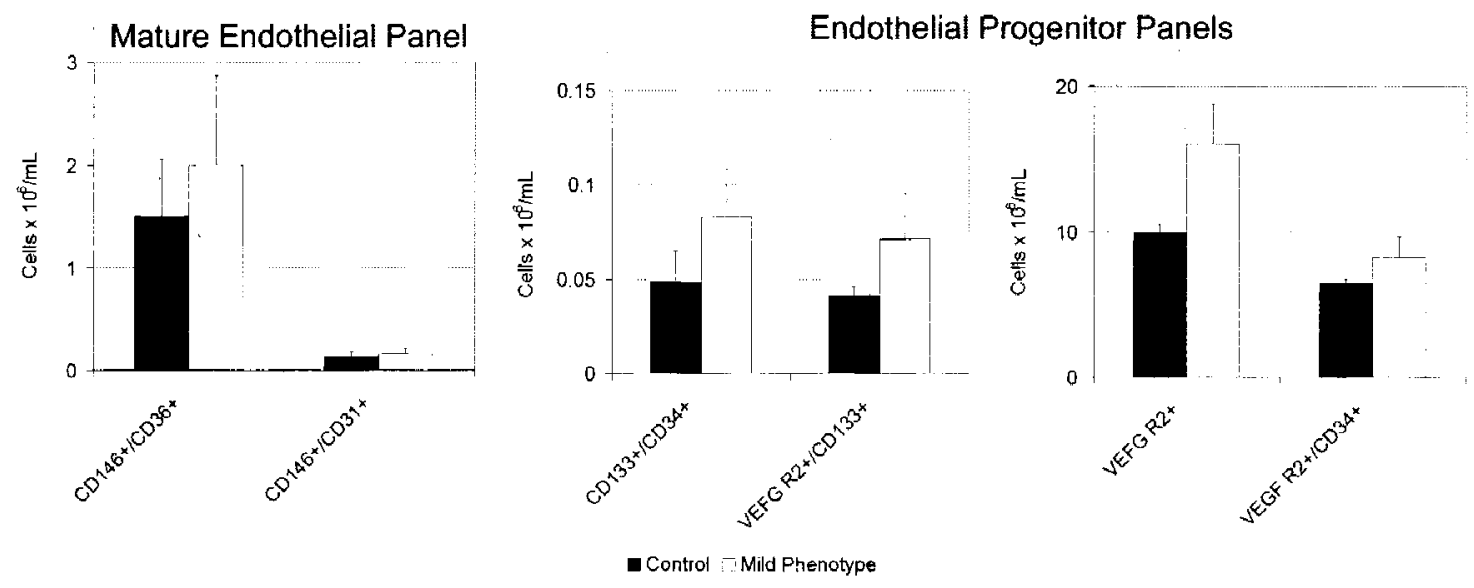

Figure 10. Endothelial panel.

Figures 8-10 show comparisons of actual cell counts per $\mathrm{mL}$ of whole blood in controls and mild phenotype SCD patients. From the data it can be seen that the leukocyte (lymphoid and myeloid) and circulating endothelial counts (mature and progenitor) are higher in mild phenotype SCD patients. There is no selective increase in any subpopulation; rather, there are proportional increases of about 2 fold in all subpopulations. Exceptions include B cells, Myelocytes and the Granulcoyte subpopulation where there was a 3-4 fold increase. Figure 11 shows the comparison of various activation markers between the two groups. Results show that there is no statistically significant increase (Rank Sum Test) with a confidence of $\mathrm{p}=0.05$ in expression of activation markers between the groups. 


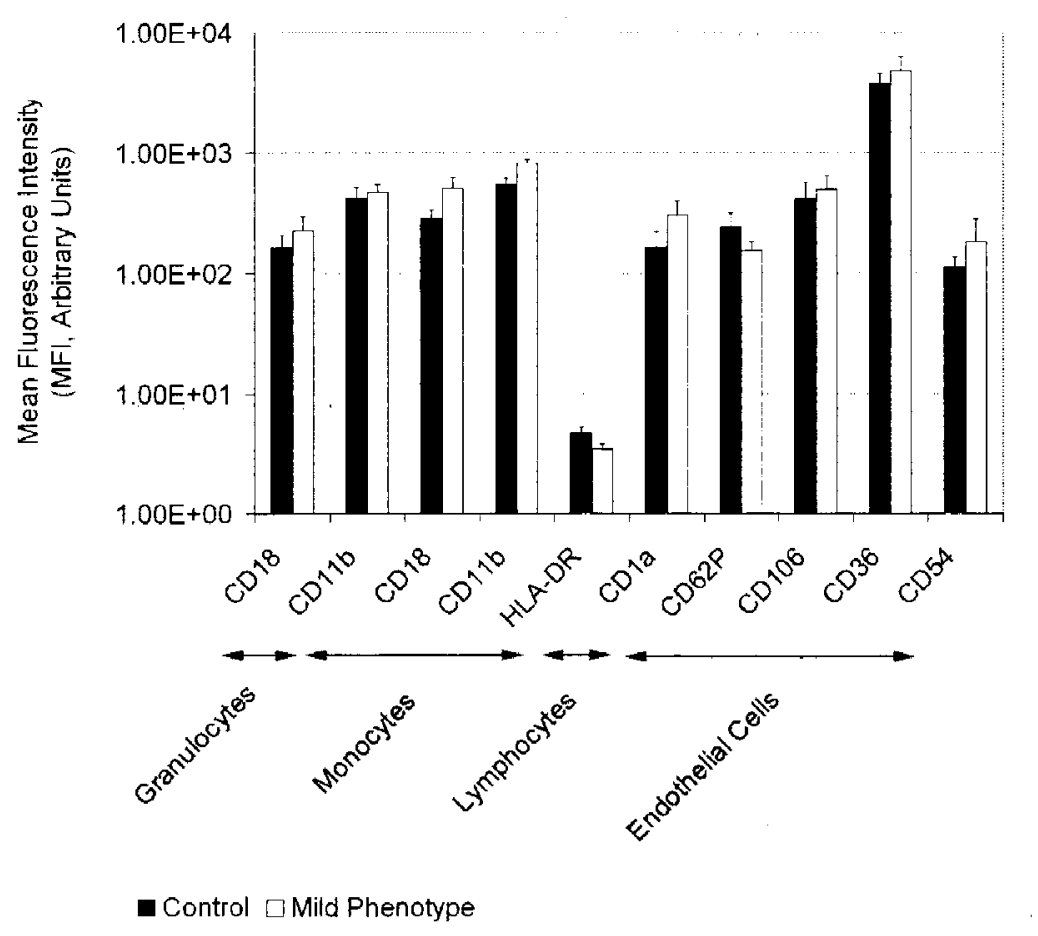

Figure 11. Activation of nucleated cells.

\subsection{DISCUSSION}

SCD serves as an excellent model to show the superiority of the microfluidic protocol as a sample preparation technique toward clinical studies. Published literature indicates that SCD patients have abnormally high leukocyte counts in peripheral blood and that activation markers are expressed during periods of vasoocclusive crisis. Leukocytes also interact with the damaged endothelium layer and may contribute to vasoocclusion [19]. With many cell types present in the pathogenesis of SCD, it is important to accurately determine those playing a major role. By analyzing the activation status and gene expression profile of the circulating cell populations in SCD patients, the mechanism of vasoocclusion can be realized and treated. Sample preparation technique without cell loss 
and artifactual activation will therefore have a significant impact on the interpretation of the data attained from a study.

Results comparing the microfluidic protocol to $\mathrm{NH}_{4} \mathrm{Cl}$ mediated lysis and Ficol density gradient separation have been presented. Minimal loss and artifactual activation of circulating cell populations were exhibited and graphical comparison is shown in Figure 7 and Table 3, respectively. Microfluidics proved to be superior for use in SCD patients. Next the panel was expanded and the microfluidic protocol was used to comprehensively profile the circulating cell populations in mild phenotype SCD patients. Markers for leukocytes and circulating endothelial cells were obtained from literature as the most widely used for each population in terms of phenotype and activation using flow cytometry [21-25]. Results from this part of the study indicate that mild phenotype SCD patients have a non-selective increase in leukocyte counts as compared to healthy controls, as shown in Figures 8 and 9. Increase in mature and progenitor endothelial cells was not significant, depicted in Figure 10. The most substantial result, illustrated in Figure 11, shows no statistical difference in activation between mild phenotype SCD patients and healthy controls.

Significance of this data can be interpreted in terms of the role of leukocytes in vasoocclusive crisis in SCD patients. SCD patients in this study were mild phenotype and not in a state of pain crisis. However, leukocyte levels were still elevated compared to controls, although not activated. This study therefore provides evidence that leukocytes in mild phenotype SCD patients are not in a chronic state of inflammation; rather high 
leukocyte counts represent a state, highly favorable for development of an inflammatory response in reaction to a given stimulus. As for circulating endothelial counts, both mature and progenitor endothelial cells were not activated in SCD patients compared to controls. Circulating mature endothelial cells were most likely present due to damage and displacement from the blood draw or from sickle erythrocytes damaging the endothelium layer. Very few, inactivated progenitor endothelial cells were found in circulation. 


\section{CHAPTER V - STUDY OF MILD PHENOTYPE SCD AND SYMPTOMATIC}

\section{$\underline{\text { SCD }}$}

\subsection{INTRODUCTION}

In this study blood was sampled from mild phenotype $(\mathrm{n}=11)$ and symptomatic SCD patients $(n=11)$. Each sample was enriched for nucleated cells using the microfluidic lysis device and analyzed using flow cytometry. The panel of activation markers was expanded from the previous study. A similar comparative approach was taken to analyze samples from mild phenotype and symptomatic SCD patients.

\subsubsection{MOTIVATION FOR STUDY}

Clinical potential of this device to enrich leukocytes and understand disease processes is tested. In the previous study a baseline leukocyte count and activation status was set for healthy controls and mild phenotype SCD patients [18]. The objective of this study was to compare percentage of nucleated cell populations and activation of these populations between mild phenotype and symptomatic SCD patients. Using the microfluidic lysis device to enrich nucleated cell populations and flow cytometry analysis, a direct comparison between the two categories of SCD patients was made to search for a possible marker that may indicate and/or play a role in the onset of vasoocclusive crisis. 
Several studies have been carried out comparing mild phenotype and symptomatic SCD patients. With no consensus on the events leading up to a vasoocclusive crisis [10], several articles have suggested the importance of epigenetic effects on the mutated $\beta$ globin gene in SCD that produces extreme variability in clinical expression among individuals [14, 26-28], while others have proposed the importance of certain expression markers on leukocyte populations that may indicate the inevitability of a painful episode $[13,15,19,29]$. By staining for these possibly relative expression markers, each

population of nucleated cells was examined according to phenotype, accomplishing enrichment with the microfluidic lysis device, to determine if a difference in expression between groups or individuals exists. Other studies analyzing expression markers utilized conventional techniques for enumeration, therefore prone to cell loss and artifactual activation, skewing results and deduced conclusions [11]. Hence, clinical expression of markers among individuals may be too variable to investigate. Accurately determining activation status of nucleated cell populations among mild phenotype and symptomatic SCD patients will aid in the comprehension and prevention of vasoocclusive crises.

\subsection{METHODS}

This study was done in collaboration with Dr. Ashok Raj and Dr. Salvatore J. Bertolone at the center for Pediatric Hematology/Oncology, School of Medicine, University of Louisville. Facilities at the Flow Cytometry Core, James Graham Brown Cancer Center, University of Louisville were utilized to run samples, assisted by Dr. Sam Wellhausen. The following section briefly explains the process by which the experiments were carried 
out during this study. It includes patient classifications, protocol for the microfluidic lysis enrichment and flow cytometry sample and data analysis.

\subsubsection{BLOOD SAMPLES}

Blood collection was approved by the Institutional Review Board of the University of Louisville. After obtaining written consent, $4 \mathrm{~mL}$ of blood were drawn from a total of 11 mild phenotype and 11 symptomatic SCD patients with sodium heparin as anticoagulant (Vacutainer $^{\mathrm{TM}}$, Becton Dickinson, Franklin Lakes, NJ).

\subsubsection{SAMPLE CLASSIFICATION}

Mild phenotype SCD patients contained copies of both alleles of the sickle cell trait and were of African-American descent between the ages of 10 to 19 with no vasoocclusive crisis. Symptomatic SCD patients were receiving pheresis treatment for vasoocclusive episodes. Refer to section 3.3 for further details on patient sample classification.

\subsubsection{MICROFLUIDIC LEUKOCYTE ENRICHMENT}

A microfluidic lysis device similar to the device described by Sethu et al [20] was used for enrichment of leukocytes and circulating nucleated cells from whole blood. The device allows for whole blood to rapidly mix with deionized water in a 1:30 ratio for approximately 10 seconds. Detailed theory, mechanism and protocol for the device can be found in section 2. The remaining cells are returned to isotonic conditions at the exit of the device and fixed using $2 \%$ paraformaldehyde (PFA). Following centrifugation to remove erythrocyte debris, the remaining leukocytes were suspended in a flow buffer 
containing $1 \%$ bovine serum albumin (BSA), $1 \%$ PFA and $0.1 \%$ sodium azide for staining and flow cytometry.

\subsubsection{FLOW CYTOMETRIC ANALYSIS}

Different subpopulations were assessed by flow cytometry. Cells were visualized using peridin chlorophyll-a (PerCP), fluorescein isothiocyanate (FITC), phycoerythrin (PE) and allophycocyanin (APC) conjugated antibodies (BD Biosciences, San Jose, CA) against leukocyte phenotype and activation cell-surface markers. Conjugated antibodies VEGF R2/KDR (R\&D Systems, Minneapolis, MN) and CD133 (Ancell Co., Bayport, MN) were also used to visualize endothelial cells. Refer to Table 4 for list of markers. Stained cells were washed in $1 \% \mathrm{HAB}$ (Hank's balanced salts without calcium or magnesium, plus $1 \%$ bovine serum albumin, $0.1 \%$ sodium azide, and $1 \mathrm{mM}$ ethylenediamine tetraacetic acid), pelleted, resuspended in $\mathrm{HAB}$, and analyzed on a FACSCalibur ${ }^{\mathrm{TM}}$ flow cytometer (BD Biosciences, San Jose, CA), using CellQuest ${ }^{\mathrm{TM}}$ software (BD Pharmingen). Cell expression was scored using the Rank Sum Test. All data correspond to the means of total percentage of cells or relative high percentage of regioned populations, \pm S.E.M., for mild phenotype $(\mathrm{n}=11)$ and symptomatic $\operatorname{SCD}(\mathrm{n}=11)$. 


\section{Table 4}

Nucleated cell populations and corresponding phenotype and activation markers

\begin{tabular}{|c|c|c|c|}
\hline Cell Type & Phenotype Marker & Cell Type & Activation Marker \\
\hline \multirow{4}{*}{ Endothehal Progenitor } & $\mathrm{CD} 34+/ \mathrm{CD} 133+/ \mathrm{CD} 1+$ & \multirow{3}{*}{ Endothelial Mature } & CD106 \\
\hline & $\operatorname{CD} 34+/ \operatorname{CD} 133+/ \operatorname{CO} 1+$ & & $\mathrm{CD} 62 \mathrm{P}$ \\
\hline & $\mathrm{CD} 34+/ \mathrm{CO} 133+/ \mathrm{NEGFR2}+$ & & $\operatorname{co5} 5$ \\
\hline & $\operatorname{CD} 34+/ C D 133+/ C D 138+$ & \multirow{6}{*}{ Monocyte/Granulocyte } & $\mathrm{CD} 64$ \\
\hline Endothelial Mature & $\operatorname{CD} 146+/ C D 31+/ C D 36+$ & & $\mathrm{CD} 49 \mathrm{~d}$ \\
\hline Granulocyte & $c 066 b+$ & & CD162 \\
\hline Monocyte/Macrophage & CD14t & & CD62L \\
\hline \multirow{3}{*}{ Lymphocyte } & $\mathrm{CO} 3+/ \mathrm{CO} 4 *$ & & CD18 (Mon) \\
\hline & $\mathrm{CO} 3+/ \mathrm{CO}_{4}$ & & CD61 (Gran) \\
\hline & $\mathrm{CD} 25+/ C D 4+$ & Lymphocyte & $\operatorname{CD} 69$ \\
\hline WBC & CD45t & & \\
\hline
\end{tabular}

\subsubsection{FLOW CYTOMETRY DATA ANALYSIS}

Flow cytometry data files were analyzed using WinMDI software (Scripps Institute, Flow Cytometry Core Facility, San Diego, CA). Each data file was manually gated and analyzed using different combinations of phenotype and activation markers. All fluorescence expression was normalized using controls and is represented as a percentage of nucleated cells in venous circulation.

\subsection{RESULTS}

This section summarizes the results of the expanded panel of antibodies to study the pathogenesis of SCD using the microfluidic protocol. Graphs and tables are provided. 


\subsubsection{ERYTHROCYTE DEPLETION AND LEUKOCYTE YIELD}

Blood samples were drawn from mild phenotype and symptomatic SCD patients and leukocytes were enriched using microfluidic lysis. Leukocytes and other circulating nucleated cell populations were phenotyped and their percentages were determined. Circulating nucleated cells were phenotyped and split into the following panels: Leukocytes (Figure 12) and Endothelial (Figure 13). Leukocytes were phenotyped using fluorescently labeled antibodies as $\mathrm{CD} 3+\mathrm{CD} 4+\mathrm{Th} 1$ and $\mathrm{Th} 2, \mathrm{CD} 3+\mathrm{CD} 4-\mathrm{CTL}$, CD4+CD25+ Treg cells, CD14+ Monocytes, CD66b+ Granulocytes and CD45+ Leukocytes. Endothelial panel included Mature Endothelial CD146+CD36+CD31+ and Progenitor Endothelial CD133+CD34+CD61+, CD133+CD34+CD31+, CD133+CD34+CD138+ and CD133+CD34+VEGF R2+. Panels were evaluated using 4 color flow cytometry. Results in percentage of total nucleated cells (Figures 12-13) indicate that no definitive difference can be seen $(\mathrm{p} \geq 0.05)$ between mild phenotype and symptomatic SCD patients.

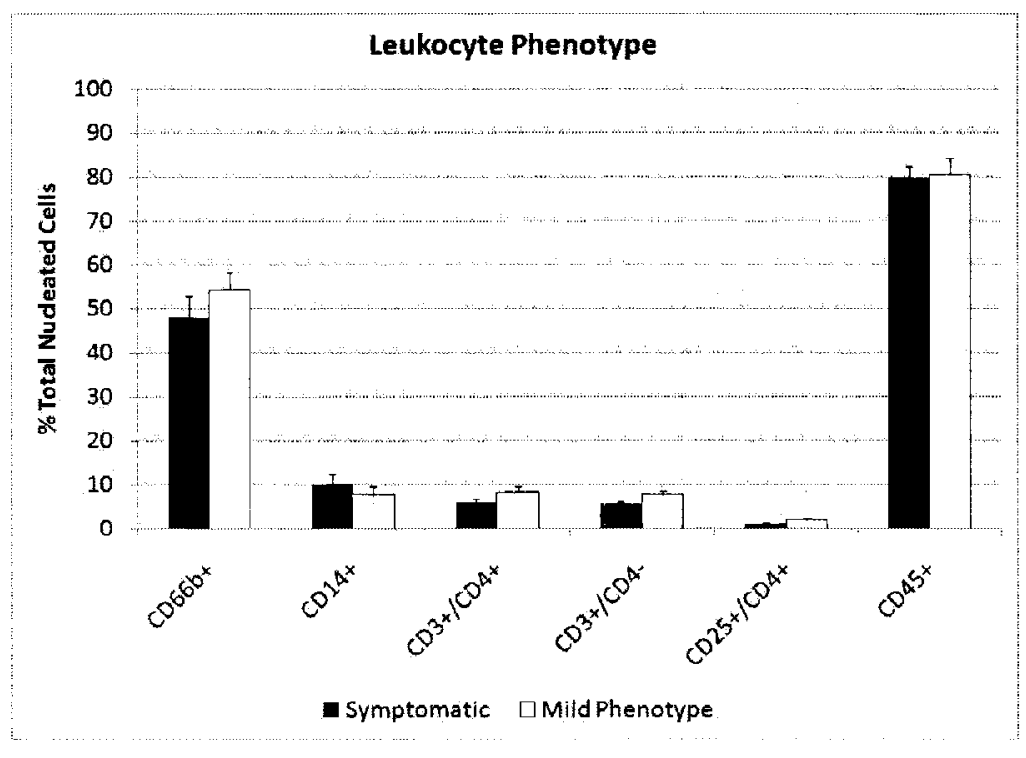

Figure 12. Leukocyte phenotype panel. 


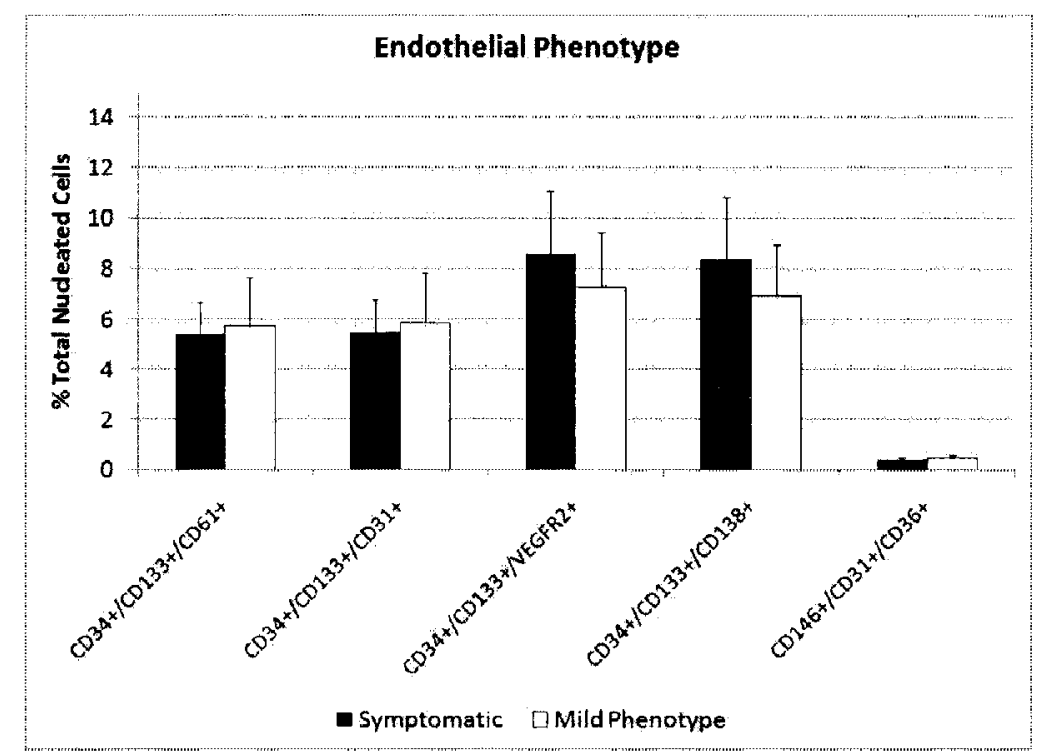

Figure 13. Endothelial phenotype panel.

\subsubsection{LEUKOCYTE ACTIVATION MARKERS IN SCD}

Mild phenotype and symptomatic SCD samples were analyzed comprehensively using the microfluidic enrichment protocol. Activation markers for several leukocyte and circulating endothelial cell populations were measured. Expression of activation markers was quantified for CD64, CD49d, CD18, CD162 and CD62L on Monocytes (Figure 14), CD64, CD49d, CD61, CD162 and CD62L on Granulocytes (Figure 15), CD69 on Lymphocytes (Figure 16) and ICAM-1 (CD54), VCAM-1 (CD106) and P-Selectin (CD62p) on circulating Endothelial Cells (Figure 17). 


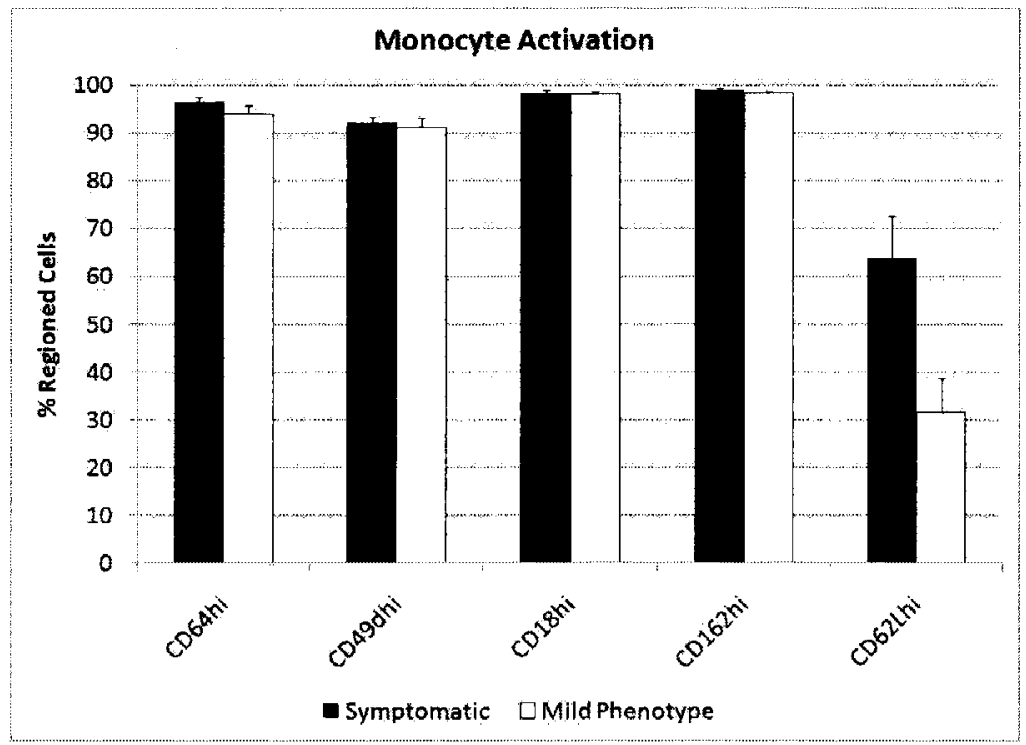

Figure 14. Monocyte activation panel.

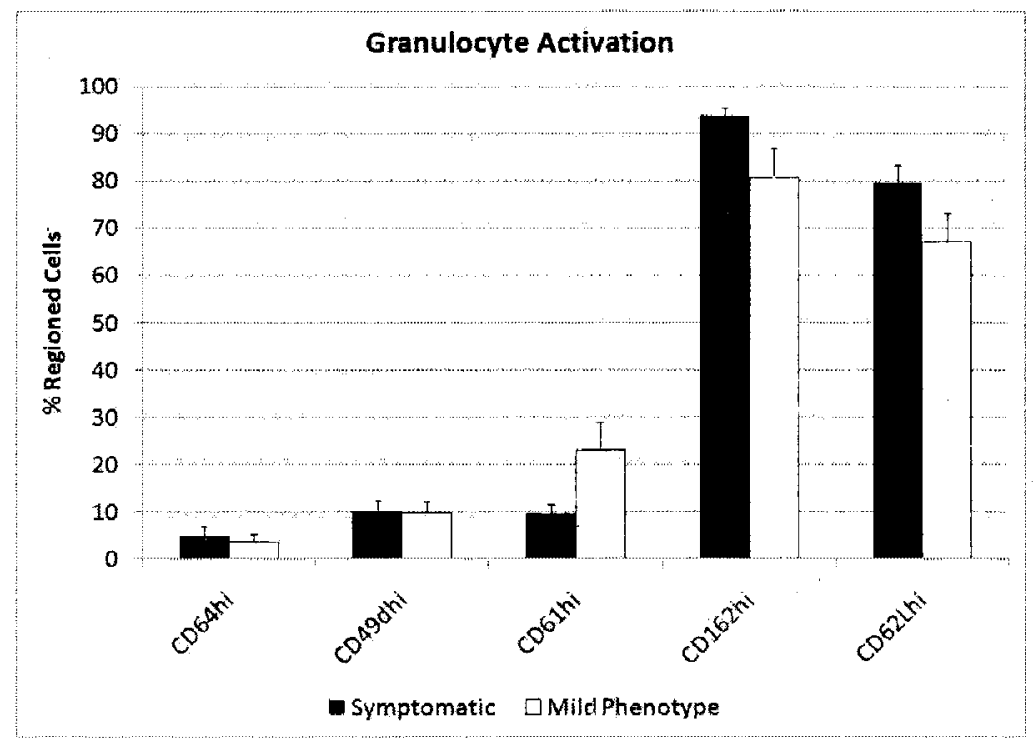

Figure 15. Granulocyte activation panel. 


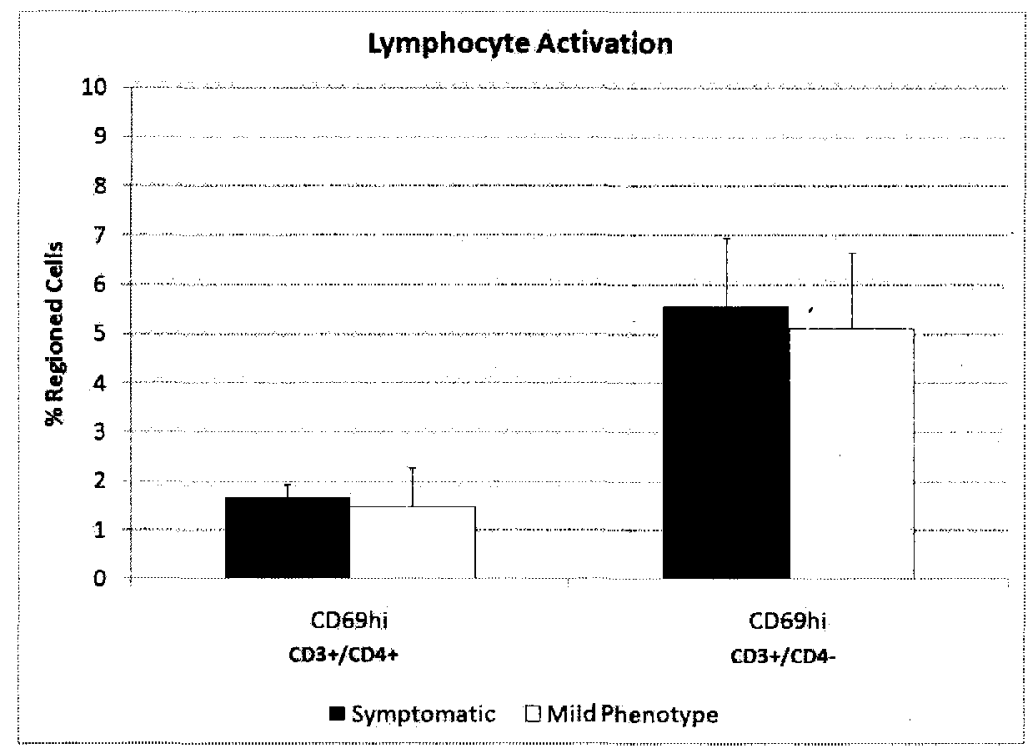

Figure 16. Lymphocyte activation panel.

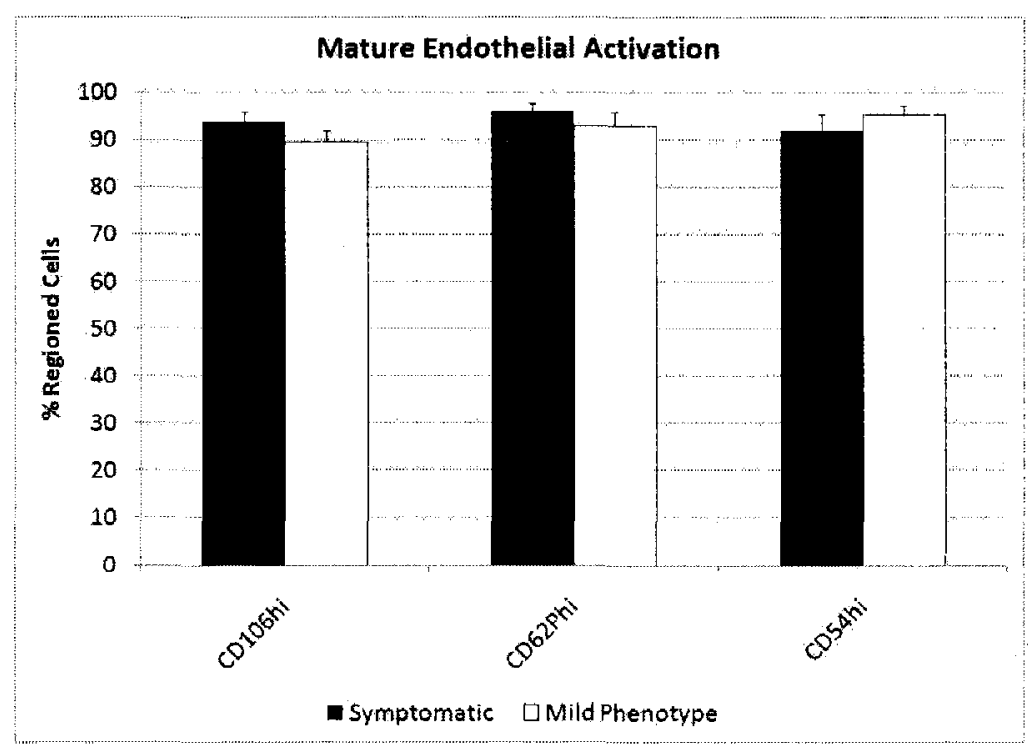

Figure 17. Endothelial activation panel.

Figures 12-13 show comparisons of percentage of total nucleated cells in mild phenotype and symptomatic SCD patients. From the data it can be seen that there is no significance between leukocyte (lymphoid and myeloid) and circulating endothelial counts (mature 
and progenitor). However, there is a large variance among patient samples; hence, Table 5 depicts percentage of total nucleated cells (Leukocyte and Endothelial) ranging from high to low. Figures 14-17 show the comparison of various activation markers between the two groups, based on Leukocyte and Endothelial subpopulations. Results show that there is no statistically significant increase (Rank Sum Test) with a confidence of $p \geq$ 0.05 in expression of activation markers between the groups, with the exception of a significant difference (Figure 14) of CD62L expression on Monocytes ( $p<0.01$ ). Since there is still a large variance among patient samples, Table 6 depicts percentage of regioned nucleated cell populations (Leukocyte) ranging from high to low.

\section{Table 5}

Ranked values of percentage of total nucleated cells

\begin{tabular}{|c|c|c|c|c|c|c|c|c|c|c|c|c|c|c|c|}
\hline & & & \multicolumn{11}{|c|}{ Highest to lowest } & \multirow{2}{*}{$\begin{array}{c}\text { Avg } \\
48.14\end{array}$} & \multirow{2}{*}{$\begin{array}{l}\text { SEM } \\
4.73\end{array}$} \\
\hline & \multirow{2}{*}{ CD66b- } & Sym & 70.64 & 68.85 & 61.34 & 56.51 & 51.59 & 47.13 & 45.25 & 44.27 & 30.17 & 29.55 & 24.22 & & \\
\hline & & Mild Phen & 76.34 & 67.43 & 66.12 & 1.19 & 57.70 & 85 & 59 & 46.22 & $42.40^{\circ}$ & 35.89 & 34.09 & 17 & 06 \\
\hline & CD14t & Mild & 39 & .14 & 12.49 & 29 & 6 & 2 & 4.83 & 2.62 & 60 & 2.20 & 1.85 & 1 & 81 \\
\hline & $\mathrm{CD} 3+/ \mathrm{CD} 4+$ & ic: & 26 & 7.75 & 33 & 33 & 6.54 & 630 & 5.87 & 5.43 & 4.46 & 32 & 2.51 & 0 & 56 \\
\hline \multirow{3}{*}{$\begin{array}{l}\text { Total } \\
\text { Cells }\end{array}$} & & Mild & 13.76 & 12,59 & 9.30 & 9.11 & 8 & 1.000 & 6.44 & 6.14 & 3.34 & 3.01 & 5 & & 8 \\
\hline & \multirow{2}{*}{$\mathrm{CD} 25+/ \mathrm{CO} 4 *$} & tic & 1.43 & 41 & 1.39 & 1.36 & .2 & 1.0 & 0.98 & 0.85 & .74 & 0.65 & .20 & 1.03 & 12 \\
\hline & & Mild & 4.79 & 1 & 3.24 & 2.49 & 1 & & & 0.51 & 0.49 & 7 & 2 & & 0.49 \\
\hline \multirow{5}{*}{$\begin{array}{c}\% \\
\text { Total } \\
\text { Cells }\end{array}$} & $\mathrm{CD} 34+/ \mathrm{CDI} 33+/$ & tomatic & 14.94 & 10.71 & 6.81 & 6.70 & 4 & & & 3.53 & 3,08 & 3 & 8 & & \\
\hline & CD6It & Mild Phenotype & 17.60 & 16.77 & 11.17 & 6.21 & 3.2 & & & 1.70 & 0.5 & 0.37 & 7 & & 96 \\
\hline & VEGFR2* & Mild Phenotype & 26.55 & 9.66 & 9.45 & 7.93 & 6.90 & 6.23 & 6.19 & 3.84 & 1.82 & 0.98 & 0.34 & 7.26 & 2.16 \\
\hline & $\cos 4+/ \operatorname{col} 33+/$ & mptomatic & 28.82 & 18.12 & 9.59 & 7.11 & 6.96 & 6.47 & 4.97 & 3.76 & 3.49 & 1.51 & 1.45 & 9 & 2.47 \\
\hline & 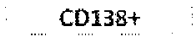 & enotype & 24.81 & 9.34 & 8.99 & 7.33 & 6.70 & 6.19 & 6.10 & 3.81 & 1.97 & 0.91 & 0.29 & 15 & 2.01 \\
\hline & $\operatorname{col} 46+/ \operatorname{CD} 31+/$ & Symptomatic: & 5 & 7 & 69 & If & 0.37 & 37 & 03 & 0.21 & 0.19 & 0.12 & 0.11 & 1 & 0.08 \\
\hline & CD36* & ld & 1 & 0.58 & 0.54 & 0 & 0.49 & 0,87 & 7 & 0.19 & 0 & 0.10 & 0.09 & 5 & 0.11 \\
\hline & \multirow{2}{*}{$45+$} & & 7 & 9 & 33 & 1 & 8 & 0 & 2 & 2 & 70.90 & 8 & 76 & 1 & 2.67 \\
\hline & & Mild Phenotype & 96.43 & 93.10 & 92.96 & 90.34 & 89.61 & 79.06 & 73.90 & 73.84 & 72.47 & 61.89 & 61.42 & 80.46 & 3.8 \\
\hline
\end{tabular}




\section{Table 6}

\section{$\underline{\text { Ranked values of percentage of regioned nucleated cell populations }}$}

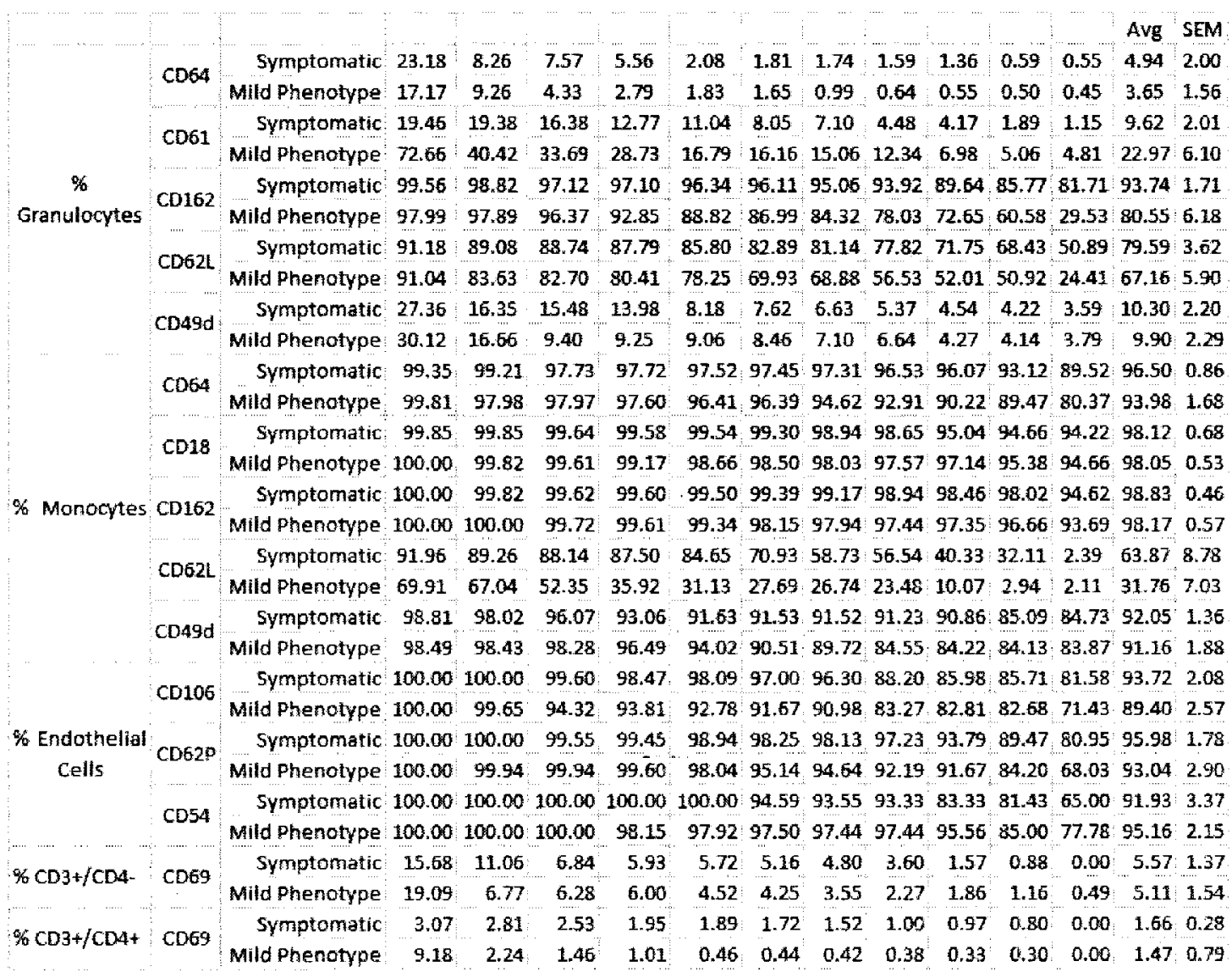

\subsection{DISCUSSION}

Published literature indicates that $\mathrm{SCD}$ patients that certain activation markers are expressed during periods of vasoocclusive crisis. Leukocytes interact with sickle erythrocytes and damaged endothelium layer through these activation markers and may contribute to vasoocclusion [19]. Hence, it is important to accurately determine the activation status and gene expression profile of the circulating cell populations in SCD patients in order to realize and avert the onset of vasoocclusion. Interpretation of 
activation status will be affected by sample preparation technique without cell loss and artifactual activation, significantly impacting the study.

Data was first scored by percentage of a nucleated cell population according to phenotype marker in terms of total nucleated cells enriched by microfluidic lysis. Each population was then analyzed by activation markers and the percentage of the population exhibiting relative high activation was recorded. Markers for leukocytes and circulating endothelial cells were obtained from literature as the most widely used for each population in terms of phenotype and activation using flow cytometry $[18,29,30]$. Results comparing mild phenotype and symptomatic SCD patients have shown on average that no statistical difference exists based on percentage of nucleated cell populations and activation of these populations between the two groups, as shown in Figures 12-17. Rather, the percentages vary from among patients in each group, with coinciding upper and lower values, depicted in Tables 5-6. Although a statistical exception arises with CD62L on CD14+ Monocytes (Figure 14), activation of this marker still notably varies among mild phenotype and symptomatic SCD patients (Table 6).

Significance of these results can be interpreted in terms of patient-to-patient variation. Indeed, the percentage of circulating nucleated populations and their expression of activation markers extremely fluctuates among the population, healthy controls and SCD patients alike. Hence, due to such variability, one cannot definitively denote vasoocclusive crisis by simple analysis of expression markers. Epigenetic effects influenced by possibly multiple environmental factors may therefore be the primary 
candidate for onset of crisis. Although all patients have the same genetic defect, heritable changes in the function of the gene occur without adjustments in the sequence (epigenetics). Such changes may influence the variability in expression among SCD patients. To render epigenetic effects on SCD one must first classify patients appropriately.

Interrogating the immune status of an individual by staining for expression markers may yet prove valuable. The extreme variability in the data infers that the manner by which symptomatic SCD patients are classified (mild phenotype or symptomatic) is too broad. Perhaps this system could be improved by categorizing SCD patients by age group and specific symptoms (refer to Section 3.3) prior to placement in clinical studies. Until such classification is imposed studies claiming to identify risk factors continue to be questionable. In conjunction with improving the classification of SCD patients, cell expression studies may in fact reveal markers or cell populations that play a role for particular groups of patients and possibly identify epigenetic effects. Such information could lead to more personal and specific therapies for SCD rather than prescription of common treatments. 


\section{CHAPTER VI - CONCLUSIONS}

\subsection{CONCLUSIONS}

A microfluidic device and enrichment protocol of circulating nucleated cells has been reported in this thesis. Superior performance in comparison to conventional enrichment techniques has been confirmed. In particular, the microfluidic protocol prevents cell loss and artifactual activation because of controlled exposure to harsh conditions. Further, the capability of this technique to generate clinically valuable information was also determined. The device, which allows for accurate analysis of the immune status of an individual, was used to study the disease process in patients with sickle cell trait.

The first study in section 4 of the thesis compared healthy controls and mild phenotype SCD patients. Results from the study indicated a non-specific increase in all circulating nucleated cells, or no increase in any specific leukocyte population, and no activation in mild phenotype SCD compared to healthy controls. From this data it was concluded that mild phenotype patients are not in a state of chronic inflammation. Instead, these patients are in a highly favorable state for an inflammatory response due to an increased baseline leukocyte count, where a small stimulus could lead to activation of leukocytes and vasoocclusive crisis. Ultimately, the study established the baseline leukocyte counts and 
activation status in mild phenotype SCD patients, data that can be used as a control for future studies seeking to evaluate SCD patients in pain crisis.

The second study in section 5 compared mild phenotype and symptomatic SCD patients. Results from this study indicated that there is extreme variability in clinical expression among individuals. Hence, it was concluded that one cannot definitively identify a single population or marker that indicates a vasoocclusive crisis. Rather, the system used to classify patients must first be revised in order to allow reports to discover risk factors in SCD.- Overall, the study provides valuable information on the immune status of symptomatic SCD patients for evaluations seeking to measure severity of a vasoocclusive crisis.

To sum up, a microfluidic device has been developed and an enrichment protocol has been established. Changes in fluid behavior due to scaling effects have been exploited and manipulated. Processes have been achieved not feasible on the macro level. Indeed developments in technological aspects of the microfluidics field continue to prove invaluable. 


\section{CHAPTER VII - FUTURE DIRECTIONS}

\subsection{FUTURE DIRECTIONS}

Several different paths exist for potential future projects with the microfluidic lysis device. In regards to Sickle cell disease (SCD) gene expression analyses can be carried out in conjunction with the lysis device to determine genetic risk factors responsible for the onset of a vasoocclusive crisis. These studies could provide further insight along with flow cytometry in the development for more specialized treatment of SCD. Other directions include investigating the role of circulating leukocytes in various diseases, automating the device, and cell sorting for analysis of unknown nucleated populations.

\subsubsection{DEVICE AUTOMATION}

As the efficacy of the microfluidic device has been exemplified in terms of clinical use and superiority to conventional techniques, the next step is complete device automation. To gain acceptance in the clinical or research field the protocol must be simplified. Hence, a platform can be developed eliminating user preparation steps and need for external machinery, such as syringe pumps. In other words one has to simply inject the blood sample and allow the apparatus to run. Below (Figure 18) is a representation of the proposed automation. Figures $18 \mathrm{a}$ and $18 \mathrm{~b}$ depict the microfluidic lysis and sorting device in parallel with the fluids driven by a pressure source and a manifold with access 
holes to encase the microfluidic device. Means to rid of centrifugation after lysis to separate out the nucleated cell populations via cell sorting is explained in the next subsection.

(a)

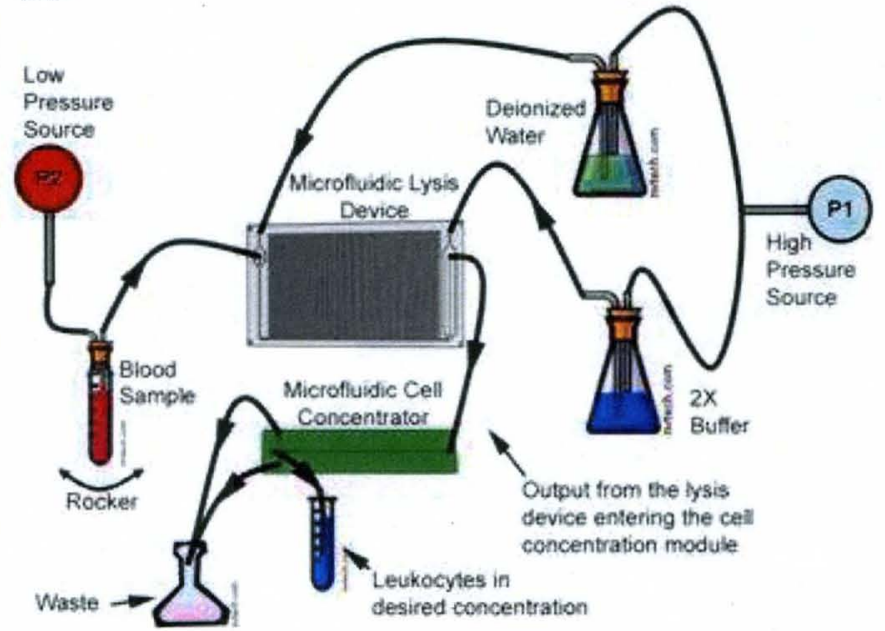

(b)

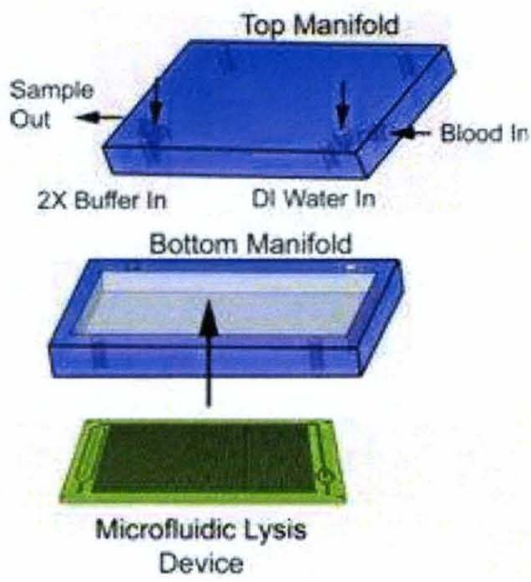

Figure 18: (a) Schematic representation of automated setup for leukocyte isolation.

(b) Solid Edge model of manifold for fluidic interconnects to microfluidic lysis device.

\subsubsection{CELL SORTING}

Cell sorting allows populations to be separated by certain characteristics, a process that could eliminate centrifugation steps in the microfluidic lysis protocol. One distinguishing feature among nucleated cell populations and red blood cell debris is size. A device has been proposed in collaboration with Aman Russom, Center for Engineering in Medicine, Massachusetts General Hospital, Harvard Medical School, that separates particles based upon size utilizing Dean flow [31]. Particles experience transverse and longitudinal forces in a curved surface. Forming a ratio of these values (transverse flow $\div$ longitudinal flow) produces a dimensionless parameter, Dean's Number, that describes the outward 
force felt by a particle [3]. Figure 19 depicts an AutoCAD drawing of the cell sorting device. Fluid enters from the center inlet via connecting tube from the lysis device. Particles exit through one of 6 ports based on size and mix with 2X PBS (outermost port) before exiting. Characterization of the sorter and combination with the lysis device would lead to an automated system.

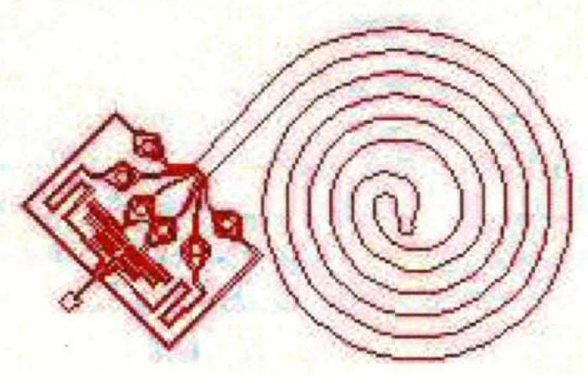

Figure 19. Schematic of proposed cell sorting device using Dean flow.

Another characteristic of nucleated cells is mass density. Based on this property cells could be allowed to sediment within a microfluidic device. Employing theoretical values for cell sedimentation as a guideline, an experimental design to sort nucleated cell populations from red blood cell debris is possible, with flow rates determining time for sedimentation. In combination with the lysis device an automated system could be produced.

\subsubsection{ANALYSIS OF UNKNOWN CELL POPULATIONS}

Using the microfluidic lysis protocol to enrich nucleated cells, many interesting populations were found in the scatter plots not typically seen with conventional 
techniques. Analysis of these unknown populations using flow cytometry or the aforementioned methods of cell sorting may lead to discovery of cell populations rarely seen in circulation. Ability to isolate and identify such populations may also lead to diagnosis of disease. 


\section{REFERENCES}

1. Whitesides, G.M., The origins and the future of microfluidics. Nature, 2006. 442(7101): p. 368-373.

2. Samuel K. Sia and George M. Whitesides, Microfluidic devices fabricated in Poly(dimethylsiloxane) for biological studies. ELECTROPHORESIS, 2003. 24(21): p. 35633576.

3. Bruus, H., Theoretical Microfluidics. 2008, New York City: Oxford University Press.

4. van Oss, C., et al., Two methods for removal of erythrocytes from buffy coats for the production of human leukocyte interferon. Immunol Commun., 1981. 10(6): p. 549-55.

5. Kouoh, F., et al., Reduced ammonium chloride haemolysis time enhances the number of isolated functional rabbit polymorphonuclear neutrophils. APMIS, 2000. 108(6): p. $417-$ 21.

6. Tait, J.F., C. Smith, and B.L. Wood, Measurement of Phosphatidylserine Exposure in Leukocytes and Platelets by Whole-Blood Flow Cytometry with Annexin V. Blood Cells, Molecules, and Diseases, 1999. 25(5): p. 271-278.

7. Irizarry, R.A., et al., Multiple-laboratory comparison of microarray platforms. Nat Meth, 2005. 2(5): p. 345-350.

8. Weis, B.K., et al., Standardizing global gene expression analysis between laboratories and across platforms. Nat Meth, 2005. 2(5): p. 351-356.

9. Stroock, A.D., et al., Chaotic Mixer for Microchannels. Science, 2002. 295(5555): p. 647651.

10. Platt, O., Sickle cell anemia as an inflammatory disease. J Clin Invest., 2000. 106(3): p. $337-8$.

11. Okpala, I., The intriguing contribution of white blood cells to sickle cell disease - a red cell disorder. Blood Reviews, 2004. 18(1): p. 65-73.

12. Abbas, A.K. and A.H. Lichtman, Basic Immunology: Functions and Disorders of the Immune System. 2001, Philadelphia: W.B. Saunders Company. 
13. Turhan, A., et al., Primary role for adherent leukocytes in sickle cell vascular occlusion: $A$ new paradigm. Proceedings of the National Academy of Sciences, 2002. 99(5): p. 30473051.

14. Chies, J.A.B. and N.B. Nardi, Sickle cell disease: a chronic inflammatory condition. Medical Hypotheses, 2001. 57(1): p. 46-50.

15. Belcher, J.D., et al., Activated monocytes in sickle cell disease: potential role in the activation of vascular endothelium and vaso-occlusion. Blood, 2000. 96(7): p. 2451-2459.

16. Steinberg, M.H. and C. Brugnara, PATHOPHYSIOLOGICAL-BASED APPROACHES TO TREATMENT OF SICKLE CELL DISEASE. Annual Review of Medicine, 2003. 54(1): p. 89112.

17. Eileen M. Finnegan, A.T.D.E.G.G.A.B., Adherent leukocytes capture sickle erythrocytes in an in vitro flow model of vaso-occlusion. American Journal of Hematology, 2007. 82(4): p. 266-275.

18. White, W., et al., Clinical application of microfluidic leukocyte enrichment protocol in mild phenotype sickle cell disease (SCD). Biomedical Microdevices, 2009. 11(2): p. 477483.

19. Okpala, I., et al., Relationship between the clinical manifestations of sickle cell disease and the expression of adhesion molecules on white blood cells. European Journal of Haematology, 2002. 69(3): p. 135-144.

20. Sethu, P., et al., Continuous Flow Microfluidic Device for Rapid Erythrocyte Lysis. Anal. Chem., 2004. 76(21): p. 6247-6253.

21. Solovey, A., et al., Circulating Activated Endothelial Cells in Sickle Cell Anemia. N Engl J Med, 1997. 337(22): p. 1584-1590.

22. Vacca, A., et al., Endothelial cells in the bone marrow of patients with multiple myeloma. Blood, 2003. 102(9): p. 3340-3348.

23. Jacob George, M.D., et al., Comparative Analysis of Methods for Assesment of Circulating Endothelial Progenitor Cells. Tissue Engineering, 2006. 12(2): p. 331-335.

24. Rebecca Gusic Shaffer, S.G.A.A.G.S.A.B.J.S.M.E.R.M., III, Flow cytometric measurement of circulating endothelial cells: The effect of age and peripheral arterial disease on baseline levels of mature and progenitor populations. Cytometry Part B: Clinical Cytometry, 2006. 70B(2): p. 56-62.

25. Sethu, P., et al., Microfluidic Isolation of Leukocytes from Whole Blood for Phenotype and Gene Expression Analysis. Anal. Chem., 2006. 78(15): p. 5453-5461. 
26. Kiefer, C.M., et al., Epigenetics of [beta]-globin gene regulation. Mutation Research/Fundamental and Molecular Mechanisms of Mutagenesis, 2008. 647(1-2): p. 68-76.

27. Reed, M., W. and M. Vichinsky, E. P., NEW CONSIDERATIONS IN THE TREATMENT OF SICKLE CELL DISEASE. Annual Review of Medicine, 1998. 49(1): p. 461-474.

28. Redding-Lallinger, R. and C. Knoll, Sickle Cell Disease--Pathophysiology and Treatment. Current Problems in Pediatric and Adolescent Health Care, 2006. 36(10): p. 346-376.

29. Lard, L., et al., Neutrophil activation in sickle cell disease. J Leukoc Biol, 1999. 66(3): p. 411-415.

30. Sheley Gambero, et al., Therapy with hydroxyurea is associated with reduced adhesion molecule gene and protein expression in sickle red cells with a concomitant reduction in adhesive properties. European Journal of Haematology, 2007. 78(2): p. 144-151.

31. Russom, A., et al. Differential Inertial Focusing in Curved High-Aspect-Ratio Channels for Continuous High Throughput Particle Separation. in MicroTAS. 2008. San Diego, CA. 


\title{
CURRICULUM VITAE
}

\author{
William N. White \\ 324 Franck Avenue \\ Louisville, KY 40206 \\ (502)592-8067•wnwhit01@louisville.edu
}

\section{Education:}

UNIVERSITY OF LOUISVILLE - Louisville, KY

Master of Science

Department of Mechanical Engineering

Fall 2007 - Summer 2009

Cumulative GPA: $3.83 / 4.00$

UNIVERSITY OF KENTUCKY - Lexington, KY

Bachelor of Science

Department of Biology

Fall 2002 - Spring 2006

Cumulative GPA: 3.78/4.00

\section{Professional experience:}

Summer 2006 - Present

GRADUATE STUDENT RESEARCH ASSISTANT - UL Bioengineering, Dr. Setha

- Design and fabrication of micro-electro-mechanical systems (MEMS) devices for cell enrichment and separation with microfluidies

Summer 2007

RESEARCH ASSISTANT - Center for Engineering in Medicine, Harvard Medical School, Massachusetts Institute of Technology, Massachusetts General Hospital, Dr. Toner

- Design and fabrication of devices for DNA analysis with microfluidics

Summer 2005 - Spring 2006

RESEARCH ASSISTANT - UK Biochemistry, Dr. McCann

- Evolutionary biology of actin-binding proteins

\section{Applied experience:}

- Engineering: Design, Mechanical testing, Device testing

- Microfabrication: Photolithography, Soft lithography, Bulk and surface micromachining, Mask design, Thin film deposition, Bonding, Wet and dry etching 
- Laboratory: Cell biology, Molecular biology, Biochemistry, Tissue culture, Flow cytometry

- Software: AutoCAD, LabVIEW, Solid Edge, Dektak, WinMDI, Cell Quest Pro, PSpice, Metamorph

\section{Publications in refereed journals:}

William N. White, Ashok Raj, Mai-Dung Nguyen, Salvatore J. Bertolone, and Palaniappan Sethu, "Clinical application of microfluidic leukocyte enrichment protocol in mild phenotype sickle cell disease (SCD)", Biomedical Microdevices 11(2):477-483, April 2009.

\section{Publications in conference proceedings:}

William N. White, A. Raj, M.D. Nguyen, S.J. Bertolone and Palaniappan Sethu, "Microfluidic enumeration protocol for comprehensive profiling of nucleated cells in mild phenotype sickle cell disease (SCD)", MicroTAS 2008, San Diego, CA, June 2008.

Aman Russom, Daniel Irimia, William N. "Will" White and Mehmet Toner, "Chemicalmediated curve analysis for genotype of single nucleotide polymorphisms", MicroTAS 2008, San Diego, CA, June 2008.

William N. White, A. Raj, M.D. Nguyen, S.J. Bertolone and Palaniappan Sethu, "Comprehensive profiling of leukocytes and circulating endothelial cells in asymptomatic SCD using microfluidic isolation", ASPHO 2008, Cincinnati, OH, February 2008.

William N. White and Palaniappan Sethu, "Isolation of progenitor endothelial cells from peripheral blood using microfluidics for sickle cell disease", BMES 2007, Los Angeles, CA, June 2007.

William N. White and Palaniappan Sethu, "Isolation of $\mathrm{CD} 31^{+} / \mathrm{CD} 61^{-}$phenotype from peripheral blood with microfluidics", Methods in Bioengineering 2007, Boston, MA, May 2007.

\section{Patents and Invention Disclosures:}

- Palaniappan Sethu and William N. White, "Microfluidic Lysis", Patent Disclosure \# 08014

\section{Teaching:}

- Tissue and Molecular Biology Techniques Lab (BE 505), Teaching assistant, Summer 2009

\section{Awards and Honors:}

- Doctoral Internal Graduate Fellowship, University of Louisville, Department of Mechanical Engineering, Fall 2009 (offered) 
- Student Travel Research Grant, Twelfth International Conference on Miniaturized Systems for Chemistry and Life Sciences (MicroTAS 2008), San Diego, CA, October 2008

- $1^{\text {st }}$ place Bioengineering research, University of Louisville, Engineering Exposition 2007

- Magna Cum Laude, University of Kentucky, 2006

- Departmental Honors, University of Kentucky, Department of Biology, 2006

\section{Membership in professional societies:}

- ASPHO (American Society of Pediatric Hematology Oncology)

- BMES (Biomedical Engineering Society)

- Phi Beta Kappa/National Honor Society

- Delta Tau Delta

\section{Reviewer:}

- Lab-on-a-Chip (LOC)

\section{References:}

Available upon request 